\title{
Alpha-pinene oxidation by OH: simulations of laboratory experiments
}

\author{
M. Capouet ${ }^{1}$, J. Peeters ${ }^{2}$, B. Nozière ${ }^{3}$, and J.-F. Müller ${ }^{1}$ \\ ${ }^{1}$ Belgian Institute for Space Aeronomy, Brussels, Belgium \\ ${ }^{2}$ Department of Chemistry, University of Leuven, Leuven, Belgium \\ ${ }^{3}$ Rosenstiel School For Marine and Atmospheric Science, University of Miami, Miami, USA \\ Received: 4 May 2004 - Published in Atmos. Chem. Phys. Discuss.: 30 July 2004 \\ Revised: 3 November 2004 - Accepted: 15 November 2004 - Published: 25 November 2004
}

\begin{abstract}
This paper presents a state-of-the-art gas-phase mechanism for the degradation of $\alpha$-pinene by $\mathrm{OH}$ and its validation by box model simulations of laboratory measurements. It is based on the near-explicit mechanisms for the oxidation of $\alpha$-pinene and pinonaldehyde by $\mathrm{OH}$ proposed by Peeters and co-workers. The extensive set of $\alpha$-pinene photooxidation experiments performed in presence as well as in absence of NO by Nozière et al. (1999a) is used to test the mechanism. The comparison of the calculated vs measured concentrations as a function of time shows that the levels of $\mathrm{OH}, \mathrm{NO}, \mathrm{NO}_{2}$ and light are well reproduced in the model. Noting the large scatter in the experimental results as well as the difficulty to retrieve true product yields from concentrations data, a methodology is proposed for comparing the model and the data. The model succeeds in reproducing the average apparent yields of pinonaldehyde, acetone, total nitrates and total PANs in the experiments performed in presence of NO. In absence of NO, pinonaldehyde is fairly well reproduced, but acetone is largely underestimated.

The dependence of the product yields on the concentration of $\mathrm{NO}$ and $\alpha$-pinene is investigated, with a special attention on the influence of the multiple competitions of reactions affecting the peroxy radicals in the mechanism. We show that the main oxidation channels differ largely according to photochemical conditions. E.g. the pinonaldehyde yield is estimated to be about $10 \%$ in the remote atmosphere and up to $60 \%$ in very polluted areas. We stress the need for additional theoretical/laboratory work to unravel the chemistry of the primary products as well as the ozonolysis and nitrateinitiated oxidation of $\alpha$-pinene.
\end{abstract}

Correspondence to: $\mathrm{M}$. Capouet

(manu.capouet@aeronomie.be)

\section{Introduction}

The emissions of nonmethane organic compounds (NMOCs) released by the vegetation into the atmosphere are substantial, on the order of $1150 \mathrm{Tg}$ carbon $\mathrm{yr}^{-1}$ worldwide (Guenther et al., 1995). The species emitted, including isoprene, monoterpenes, sesquiterpenes, and oxygenated hydrocarbons (König et al., 1995; Kesselmeier et al., 1997) are mostly unsaturated, and they are therefore highly reactive towards ozone, $\mathrm{OH}$ and $\mathrm{NO}_{3}$ radicals. Their lifetimes under tropospheric conditions are calculated to range from a few minutes to a few hours (Atkinson, 2000). Their oxidation in the atmosphere has multiple impacts in both the gas and aerosol phases, in particular on the budget of tropospheric ozone, on the oxidizing capacity of the atmosphere and on the production of organic aerosols (IPCC, 2001). Since these biogenic emissions are controlled by temperature and light, they can be expected to change, and most probably to increase, in the future as a result of climate change (European Commission, 2003).

Monoterpenes are important constituents of biogenic NMOC emissions. Although they account for $10-15 \%$ of the total biogenic NMOCs emissions worldwide (Guenther et al., 2000), they are still comparable in magnitude to the total anthropogenic NMOC emissions. Their atmospheric oxidation is an important source of acetone (Jacob et al., 2002), which has been shown to be an important actor in upper tropospheric chemistry (e.g. Müller and Brasseur, 1999).

Furthermore, their degradation yields low volatility compounds which readily form organic secondary aerosols (SOA). Recent estimates of the global aerosol production from biogenic precursors (mostly terpenes) are in the range 2.5-79 $\mathrm{Tgyr}^{-1}$ (Kanakidou et al., 2000; Griffin et al., 1999; Tsigaridis and Kanakidou, 2003). This production might be influenced by human activities, e.g. through the impact of anthropogenic emissions on the levels of the terpene oxidants, or on the organic aerosol concentration (e.g. Kanakidou et al., 2000). 
Amongst the monoterpenes, $\alpha$-pinene is observed to have the highest emission rates and to be the most abundant (e.g. Rinne et al., 2000). Several experimental studies have investigated the formation of gas-phase products from its oxidation by $\mathrm{OH}$. The yield of pinonaldehyde has been estimated to range from 28 to $87 \%$ in presence of NO (Arey et al., 1990; Hatakeyama et al., 1991; Hakola et al., 1994; Nozière et al., 1999a; Wisthaler et al., 2001) and between 3 and 37\% in absence of NO (Hatakeyama et al., 1991; Nozière et al., 1999a). The experimental yields of acetone range from 4 to $11 \%$ in presence of NO (Aschmann et al., 1998; Fantechi, 1999; Nozière et al., 1999a; Orlando et al., 2000; Larsen et al., 2001; Wisthaler et al., 2001; Librando et al., 2003) and has been estimated to about $15 \%$ in absence of NO (Nozière et al., 1999a). Vanhees et al. (2001) reported pinonaldehyde and acetone yields of $82 \%$ and $6 \%$ respectively, at 100 torr. The large discrepancies between these various studies may be related to differences in the measurement techniques, in the way the yields are estimated from concentrations, and in the photochemical conditions in the reactor.

Whereas the chemistry of simple hydrocarbons is relatively well understood (Atkinson, 1994, 2000), the degradation of large NMOCs is more difficult, due to the large number of reactions involved and to the scarceness of direct laboratory investigations of these reactions. Jenkin et al. (1997) described the development of a near-explicit chemical mechanism (Master Chemical Mechanism, MCM) describing the detailed gas-phase degradation of a series of NMOCs. Its construction is based on relatively simple rules describing the kinetics and products of the numerous reactions for which no direct laboratory measurement is available. However, many reactions in the chemistry of terpenes cannot be elucidated using simple rules deduced from well-known reactions of simple and smaller compounds. Instead, theoretical analysis has proven to be essential to investigate the reactions involved in the oxidation mechanism of large hydrocarbons. In this respect, Peeters and co-workers have recently performed a thorough theoretical analysis of the $\mathrm{OH}$-initiated oxidation of $\alpha$-pinene and pinonaldehyde, its main generation product (Peeters et al., 2001; Fantechi et al., 2002; Vereecken and Peeters, 2004). They have shown that the competition between different reactions for several alkoxy and peroxy radicals leads to an unusual dependence of the product yields on chemical conditions.

In this study, a state-of-the-art mechanism for the oxidation of $\alpha$-pinene by $\mathrm{OH}$ is presented, based on these recent studies. This mechanism is implemented in a box model and tested against the extensive set of laboratory measurements performed by Nozière and co-workers. These measurements include the time profiles of precursor and product concentrations for a total of 30 experiments performed in various conditions. The experimental results are summarized in Nozière et al. (1999a). Further reference of this paper will be abbreviated as $\mathrm{N} 99$.
Note that aerosol formation is neglected in this study. Several groups (Hatakeyama et al., 1991; N99; Bonn and Moortgat, 2002) reported aerosol measurements from the $\alpha$-pinene oxidation by $\mathrm{OH}$. The role of gas-particle partitioning for the least volatile compounds (i.e. hydroxy nitrates, peroxy acyl nitrates) will be discussed in Sect. 3.3. It cannot be ruled out that keto-aldehydes (e.g. pinonaldehyde) could partition to the aerosol phase in some conditions, in spite of their higher volatility (Hallquist et al., 1997), for example, by hydration or polymerization in presence of an acid catalyst. However, given the lack of evidence for such processes in the $\alpha$-pinene oxidation experiments discussed here, their role will be ignored.

\section{Model description}

\subsection{Outline of $\alpha$-pinene mechanism}

As for all alkenes, $\mathrm{OH}$ reacts with $\alpha$-pinene either by $\mathrm{H}$ abstraction or by addition to the double bond, forming alkyl radicals $(\mathrm{R})$ which, upon reaction with $\mathrm{O}_{2}$, produce peroxy radicals of general formula $\mathrm{RO}_{2}$. These peroxy radicals react with $\mathrm{NO}, \mathrm{HO}_{2}$ and other $\mathrm{RO}_{2}$ radicals, generating a plethora of stable products (organic nitrates, alcohols, acids...) as well as alkoxy radicals (RO) which generally dissociate or isomerise to produce stable products or/and alkyl radicals. These radicals react with $\mathrm{O}_{2}$, ensuring the propagation of the oxidation chain. Due to the complex structure of the alkoxy radicals generated in the oxidation of terpenes, they can undergo many different chemical transformations: $1,5-\mathrm{H}$ shift, 1,7-H shift, ring closure, $\mathrm{H}$-abstraction by $\mathrm{O}_{2}$, and decomposition. The rates of these reactions lie in a broad range between $1 \mathrm{~s}^{-1}$ to $10^{11} \mathrm{~s}^{-1}$.

The extensive theoretical kinetic study of the degradation of both $\alpha$-pinene and its main primary product, pinonaldehyde, by $\mathrm{OH}$ conducted by Peeters and co-workers are based on quantitative structure-activity relationships (SARs) and on DFT (density functional theory) calculations of barrier heights, in combination with statistical rate theories (Transition state theory and RRKM theory). Figures 1 and 2 summarize the main first steps in the oxidation of $\alpha$-pinene and pinonaldehyde, respectively. For a detailed description of the theoretical determination of the fates and rates of the oxy radicals, we refer to the here above cited publications.

The main routes of the $\alpha$-pinene degradation are the $\mathrm{OH}$ addition channel (via 2 paths: $R_{2}$ and $R_{6}$ in Fig. 1) and an $\mathrm{H}$-abstraction channel (via $\mathrm{R}_{1}$ ), accounting for $88 \%$ and $9 \%$, respectively. Minor $\mathrm{H}$-abstraction channels (3\%) are not considered explicitly in our mechanism and are assumed to follow the same chemistry as the main abstraction channel. It can be seen in Fig. 1 that several peroxy radicals produced by the oxidation of $\alpha$-pinene can react in quite unusual ways, like e.g. the decomposition reaction of $\alpha$-hydroxyalkyl peroxy radicals (e.g. $\mathrm{R}_{3} \mathrm{O}_{2}, \mathrm{R}_{13} \mathrm{O}_{2}$ ) described by Peeters et al. 


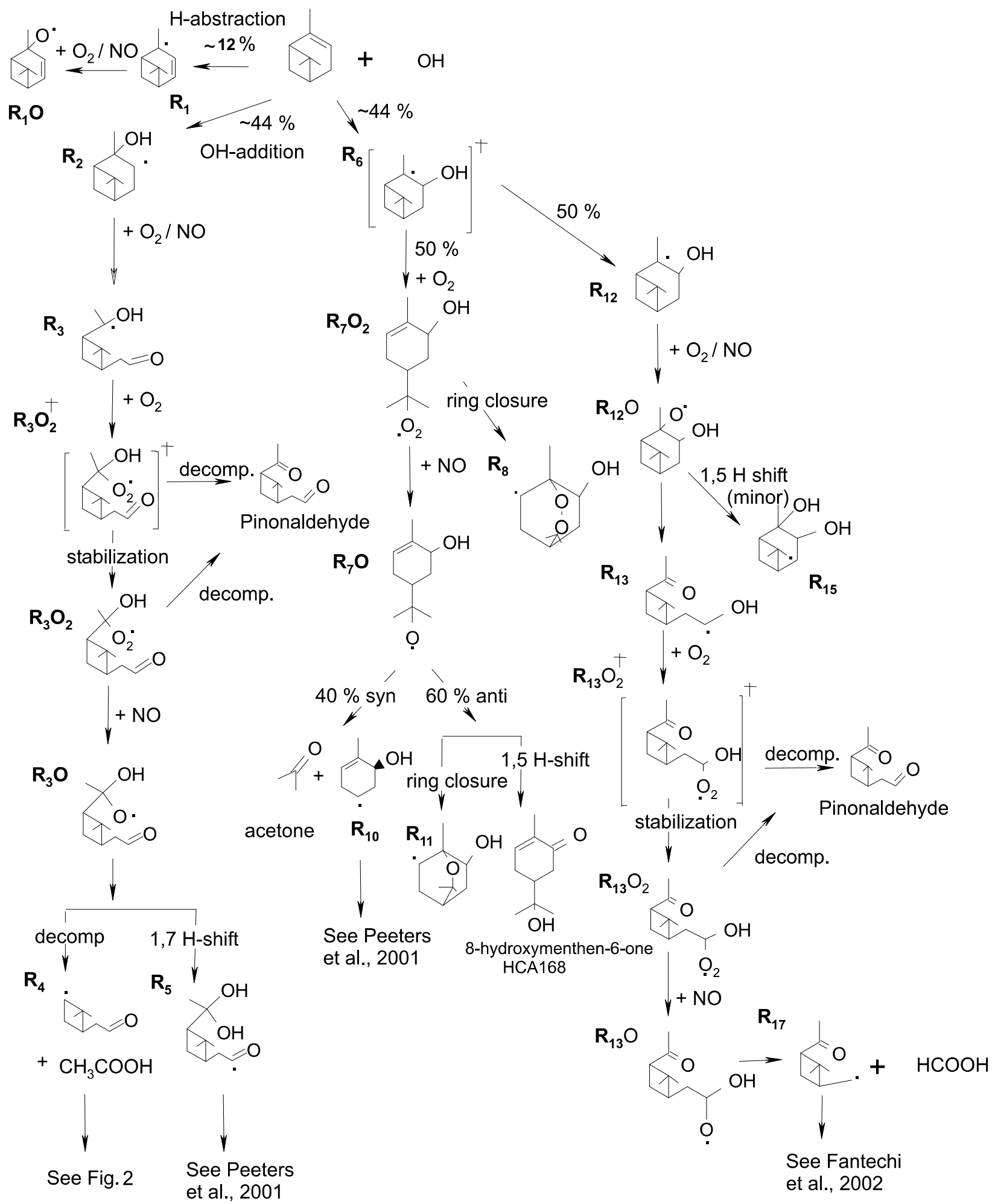

Fig. 1. Main paths of the $\alpha$-pinene oxidation by $\mathrm{OH}$. 


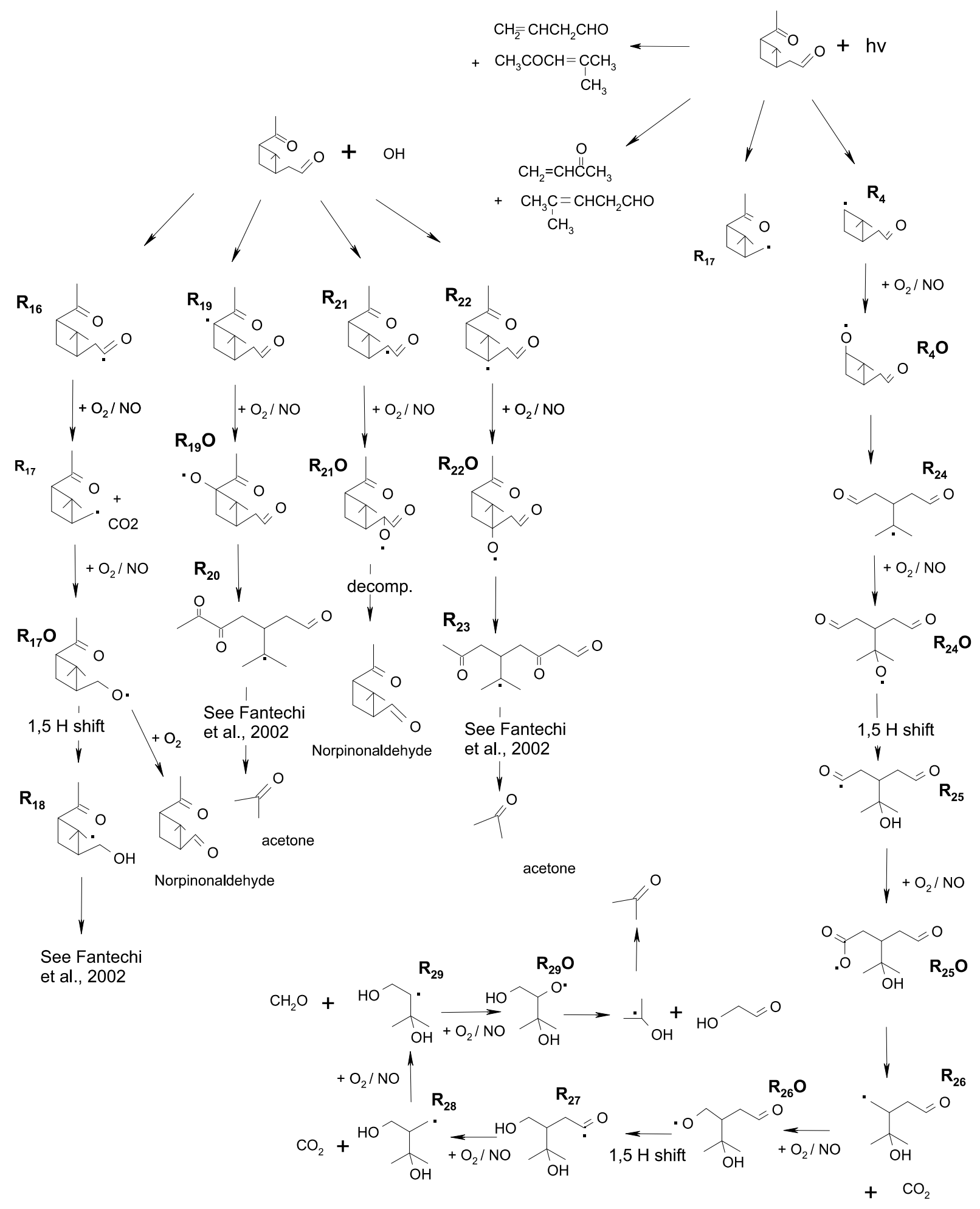

Fig. 2. Main paths of the $\mathrm{OH}$-oxidation and photolysis of pinonaldehyde. 
(2001) and by Hermans et al. (2004) $)^{1}$ and the ring closure reactions of large unsaturated peroxy radicals (e.g. $\mathrm{R}_{7} \mathrm{O}_{2}$ ) (Vereecken and Peeters, 2004). These reactions can compete with the NO-reaction, affecting the yields of pinonaldehyde, acetone, and the semi-volatile aerosol precursors.

The gas-phase chemistry implemented in the model used for the present study is discussed in more detail in Sects. 2.2 to 2.4. The determination of the photolytic channels and rates are presented in Sect. 2.5. Inorganic chemistry is based on Atkinson et al. (2003).

\subsection{Reactions of peroxy radicals $\mathrm{RO}_{2}$}

\subsubsection{Reactions of $\mathrm{RO}_{2}$ with $\mathrm{NO}$}

The reaction of a $\mathrm{RO}_{2}$ radical with $\mathrm{NO}$ leads to the formation of either an alkoxy radical (RO) or an alkyl nitrate $\left(\mathrm{RONO}_{2}\right)$ :

$$
\begin{aligned}
\mathrm{RO}_{2}+\mathrm{NO} & \rightarrow \mathrm{RONO}_{2} \\
& \rightarrow \mathrm{RO}+\mathrm{NO}_{2} .
\end{aligned}
$$

The rate coefficients for $\mathrm{CH}_{3} \mathrm{O}_{2}, \mathrm{C}_{2} \mathrm{H}_{5} \mathrm{O}_{2}, \mathrm{CH}_{3} \mathrm{C}(\mathrm{O}) \mathrm{O}_{2}$ and $\mathrm{C}_{2} \mathrm{H}_{5} \mathrm{C}(\mathrm{O}) \mathrm{O}_{2}$ from the recommendations of Atkinson et al. (2003) are used for all peroxy radicals $\left(\mathrm{RO}_{2}\right)$ and acyl peroxy radicals $\left(\mathrm{RC}(\mathrm{O}) \mathrm{O}_{2}\right)$ of the same carbon number. For higher $\left(\mathrm{C}_{>2}\right)$ peroxy radicals, the expression $2.54 \times 10^{-12} \exp (360 / \mathrm{T}) \mathrm{cm}^{3}$ molecule $\mathrm{c}^{-1} \mathrm{~s}^{-1}$ proposed by Saunders et al. (2003) is used. The rate for $\mathrm{C}_{2} \mathrm{H}_{5} \mathrm{C}(\mathrm{O}) \mathrm{O}_{2}$ $+\mathrm{NO}, 6.7 \times 10^{-12} \exp (340 / \mathrm{T}) \mathrm{cm}^{3}$ molecule ${ }^{-1} \mathrm{~s}^{-1}$, is assigned to higher $\left(\mathrm{C}_{>2}\right)$ acyl peroxy radicals. The ratio $k_{R 1 \mathrm{a}} / k_{R 1 \mathrm{~b}}$ for reactions involving $\mathrm{CH}_{3} \mathrm{O}_{2}, \mathrm{C}_{2} \mathrm{H}_{5} \mathrm{O}_{2}$ and $\mathrm{CH}_{3} \mathrm{C}(\mathrm{O}) \mathrm{O}_{2}$ does not exceed 3\% (Tyndall et al., 2001) . The organic nitrate-forming channel is therefore neglected for $\mathrm{C}_{\leq 2}$ peroxy and all acyl peroxy radicals. The organic nitrates yield for other alkyl peroxy radicals is calculated using the expression of Arey et al. (2001).

\subsubsection{Reactions of $\mathrm{RO}_{2}$ with $\mathrm{NO}_{2}$}

The reaction of $\mathrm{RO}_{2}$ radicals with $\mathrm{NO}_{2}$ forms peroxy nitrates:

$\mathrm{RO}_{2}+\mathrm{NO}_{2}+\mathrm{M} \leftrightharpoons \mathrm{RO}_{2} \mathrm{NO}_{2}+\mathrm{M}$.

The Reaction (R2) involving peroxy radicals is negligible in the lower atmosphere as well as in laboratory reactors (Atkinson et al., 2003). However $\mathrm{RCO}(\mathrm{O})_{2}$ radicals react with $\mathrm{NO}_{2}$ to form stable peroxy acyl nitrates (abbreviated as PANs) of general formula $\mathrm{RC}(\mathrm{O}) \mathrm{O}_{2} \mathrm{NO}_{2}$. The main loss mechanism of PANs is thermal decomposition back to

\footnotetext{
${ }^{1}$ Hermans, I., Nguyen, T. L., Jacobs, P. A., and Peeters, J.: Kinetics and dynamics of $\alpha$-hydroxy-alkylperoxyl radicals in atmospheric chemistry and in the aerobic oxidation of alcohols and ketones, to be submitted to J. Phys. Chem. A., 2004.
}

$\mathrm{RC}(\mathrm{O}) \mathrm{O}_{2}$ and $\mathrm{NO}_{2}$. The forward reaction rate and equilibrium constant for $\mathrm{CH}_{3} \mathrm{C}(\mathrm{O}) \mathrm{O}_{2}$ are based on the recommendation of Tyndall et al. (2001). Due to the lack of additional kinetic data, Atkinson (2000) recommended to set the rate of the forward reaction of higher peroxy acyl radicals to the high-pressure limit of the Troe expression for the $\mathrm{CH}_{3} \mathrm{C}(\mathrm{O}) \mathrm{O}_{2}+\mathrm{NO}_{2}$ reaction.

\subsubsection{Reactions of $\mathrm{RO}_{2}$ with $\mathrm{NO}_{3}$}

The reaction of peroxy radicals with $\mathrm{NO}_{3}$,

$\mathrm{RO}_{2}+\mathrm{NO}_{3} \rightarrow \mathrm{RO}+\mathrm{NO}_{2}$

is treated as in Saunders et al. (2003), except that the rate of the reaction involving $\mathrm{C}_{2} \mathrm{H}_{5} \mathrm{O}_{2}$ and higher peroxy radicals is set to $2.3 \times 10^{-12} \mathrm{~cm}^{3}$ molecule ${ }^{-1} \mathrm{~s}^{-1}$ (Atkinson et al., 2003).

\subsubsection{Reactions of $\mathrm{RO}_{2}$ with $\mathrm{HO}_{2}$}

The reaction of the $\mathrm{CH}_{3} \mathrm{O}_{2}$ radical with $\mathrm{HO}_{2}$ proceeds through two channels:

$$
\begin{aligned}
\mathrm{CH}_{3} \mathrm{O}_{2}+\mathrm{HO}_{2} & \rightarrow \mathrm{CH}_{3} \mathrm{OOH}+\mathrm{O}_{2} \\
& \rightarrow \mathrm{CH}_{2} \mathrm{O}+\mathrm{H}_{2} \mathrm{O}+\mathrm{O}_{2} .
\end{aligned}
$$

Tyndall et al. (2001) recommended a room temperature rate coefficient of $5.2 \times 10^{-12} \mathrm{~cm}^{3}$ molecule ${ }^{-1} \mathrm{~s}^{-1}$ for the overall reaction. The relative importance of the $\mathrm{CH}_{2} \mathrm{O}$ branching channel is given by the temperature-dependent equation defined by Elrod et al. (2001):

$k_{R 4 \mathrm{a}} / k_{R 4 \mathrm{~b}}=\exp (6.21-1160 / \mathrm{T})$.

At $298 \mathrm{~K}$, the hydroperoxide channel is the main pathway with $k_{R 4 \mathrm{a}} / k_{R 4}=0.91$. Experimental evidence indicates that the reaction of most alkyl peroxy radicals with $\mathrm{HO}_{2}$ proceeds exclusively via the hydroperoxide pathway (Atkinson et al., 2003):

$\mathrm{RO}_{2}+\mathrm{HO}_{2} \rightarrow \mathrm{ROOH}+\mathrm{O}_{2}$.

The rates reported for $\mathrm{CH}_{3} \mathrm{O}_{2}, \mathrm{C}_{2} \mathrm{H}_{5} \mathrm{O}_{2}$ and $\mathrm{CH}_{3} \mathrm{C}(\mathrm{O}) \mathrm{CH}_{2} \mathrm{O}_{2}$ are used for all $\mathrm{C}_{1}, \mathrm{C}_{2}$ and $\mathrm{C}_{3}$ peroxy radicals respectively. The $\mathrm{RO}_{2}+\mathrm{HO}_{2}$ rates for $\mathrm{C}_{\geq 3}$ alkyl peroxy radicals are based on the parameterization of Saunders et al. (2003)

The available data for the reaction $\mathrm{CH}_{3} \mathrm{C}(\mathrm{O}) \mathrm{O}_{2}+\mathrm{HO}_{2}$ indicate a reaction rate of (Atkinson et al., 2003; Tyndall et al., 2001):

$k_{R 5, \text { acyl }}=5.2 \times 10^{-13} \exp (983 / \mathrm{T})$.

Two channels are considered:

$$
\begin{aligned}
\mathrm{RC}(\mathrm{O}) \mathrm{O}_{2}+\mathrm{HO}_{2} & \rightarrow \mathrm{RC}(\mathrm{O}) \mathrm{OOH}+\mathrm{O}_{2} \\
& \rightarrow \mathrm{RC}(\mathrm{O}) \mathrm{OH}+\mathrm{O}_{3} .
\end{aligned}
$$

The ratio $k_{R 6 \mathrm{a}} / k_{R 6}=0.785$ at ambient temperature recommended by Atkinson et al. (2003) for $\mathrm{CH}_{3} \mathrm{C}(\mathrm{O}) \mathrm{O}_{2}$ is used for all acyl peroxy radicals. 
Table 1. Branching ratios assigned to the cross reactions of a given $\mathrm{RO}_{2}$ with other peroxy radicals depending on their respective structure: primary (prim.), secondary (sec.), cyclic (cycl.) and acyl.

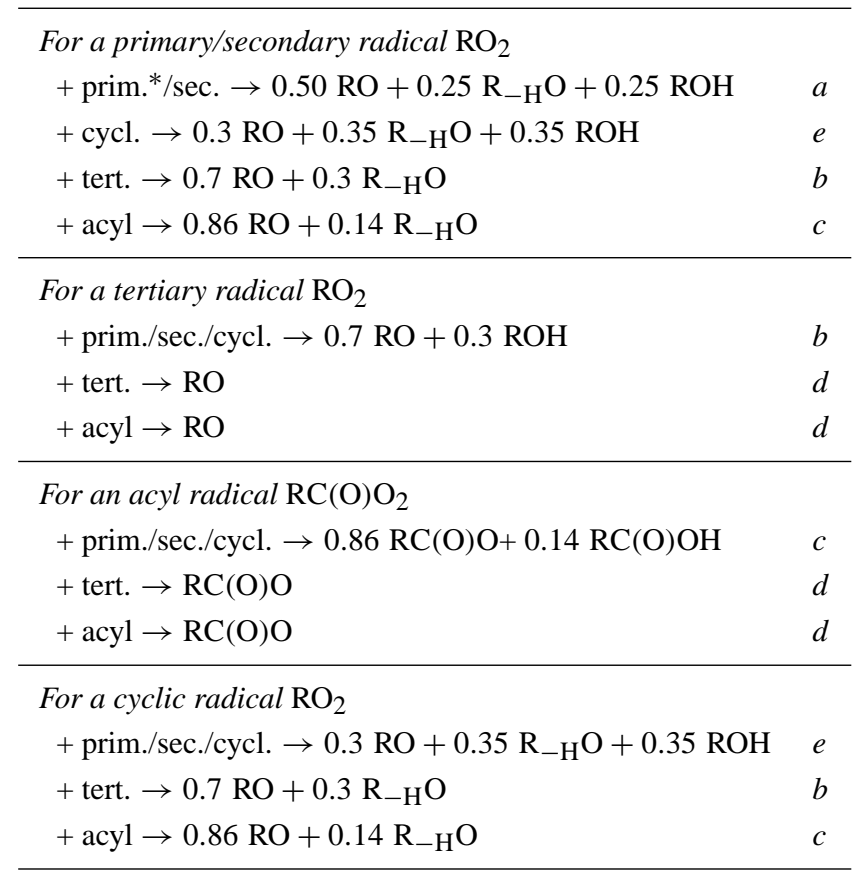

* Read "+ prim." as " $\mathrm{RO}_{2}+$ primary $\mathrm{R}^{\prime} \mathrm{O}_{2}$ ". $\quad$ a For the cross reactions of primary and secondary $\mathrm{RO}_{2}$ radicals, Atkinson (1994) suggested a constant ratio of $45 \pm 20 \%$ for the oxy-forming route at $298 \mathrm{~K}$ from the few available data of self-reactions. ${ }^{b}$ No experimental data. Value assumed. ${ }^{c}$ Based on the measurement of Horie and Moortgat (1992) for the reaction of $\mathrm{CH}_{3} \mathrm{O}_{2}$ with $\mathrm{CH}_{3} \mathrm{C}(\mathrm{O}) \mathrm{O}_{2}$ at $298 \mathrm{~K} .{ }^{d}$ Only one reaction path can occur. $e$ Based on the measurement of the self-reactions of $c-\mathrm{C}_{6} \mathrm{H}_{11} \mathrm{O}_{2}$ made by Rowley et al. (1992).

\subsubsection{Permutation reactions of $\mathrm{RO}_{2}$}

The permutation reactions of a given $\mathrm{RO}_{2}$ radical include its self-reaction and the cross reactions of this $\mathrm{RO}_{2}$ with the other peroxy radicals (Finlayson-Pitts and Pitts, 2000):

$$
\begin{aligned}
\mathrm{RO}_{2}+\mathrm{R}^{\prime} \mathrm{O}_{2} & \rightarrow \mathrm{RO}+\mathrm{R}^{\prime} \mathrm{O}+\mathrm{O}_{2} \\
& \rightarrow \mathrm{R}-\mathrm{H}_{-} \mathrm{O}+\mathrm{R}^{\prime} \mathrm{OH}+\mathrm{O}_{2} \\
& \rightarrow \mathrm{ROH}+\mathrm{R}_{-\mathrm{H}^{\prime}} \mathrm{O}+\mathrm{O}_{2} .
\end{aligned}
$$

The self-reaction of a given $\mathrm{RO}_{2}$ radical, i.e. $\mathrm{RO}_{2}+\mathrm{RO}_{2}$, undergoes the same paths. The relative importance of these paths depends on the structure of the two radicals reacting with each other. Table 1 reports the fraction of alkoxy radicals $(\mathrm{RO})$, carbonyls $\left(\mathrm{R}_{-\mathrm{H}} \mathrm{O}\right)$ and alcohols $(\mathrm{ROH})$ generated from the permutation reactions of a given $\mathrm{RO}_{2}$ radical. As shown by this table, the degree of substitution and the presence of a cycle in $\alpha$ are found to influence the branching ratios.

\begin{tabular}{|c|c|c|c|}
\hline \multicolumn{2}{|c|}{$\mathrm{RO}_{2}$ class } & \multirow{2}{*}{$\begin{array}{c}\begin{array}{c}\text { Class } \\
\text { notation }\end{array} \\
\text { R1R }\end{array}$} & \multirow{2}{*}{$\frac{\left(\mathrm{cm}^{3} \mathrm{molec}^{\mathrm{k}_{\mathrm{self}}}\right.}{4.0 \times 10^{-12}}$} \\
\hline Alkyl & primary & & \\
\hline & seconday & $\mathrm{R} 2 \mathrm{R}$ & $4.0 \times 10^{-13}$ \\
\hline & tertiary & R3R & $1.0 \times 10^{-16}$ \\
\hline \multirow[t]{3}{*}{$\beta$-hydroxy } & primary & $\mathrm{R} 1 \mathrm{H}$ & $8.0 \times 10^{-12}$ \\
\hline & secondary & $\mathrm{R} 2 \mathrm{H}$ & $3.0 \times 10^{-12}$ \\
\hline & tertiary & $\mathrm{R} 3 \mathrm{H}$ & $5.0 \times 10^{-14}$ \\
\hline \multicolumn{4}{|c|}{$\alpha$-hydroxy/ $\beta$-carbonyl/ } \\
\hline \multirow[t]{3}{*}{ multifunctional } & primary & $\mathrm{R} 1 \mathrm{M}$ & $1.5 \times 10^{-11}$ \\
\hline & secondary & $\mathrm{R} 2 \mathrm{M}$ & $1.0 \times 10^{-11}$ \\
\hline & tertiary & R3M & $1.0 \times 10^{-13}$ \\
\hline acyl peroxy & & $\mathrm{RO} 3$ & $1.5 \times 10^{-11}$ \\
\hline
\end{tabular}

Table 2. $\mathrm{RO}_{2}$ classes and self-reaction rate constants $\left(\mathrm{k}_{\mathrm{self}}\right)$ at 298 K.

Because of the large number of $\mathrm{RO}_{2}$ radicals generated in the mechanism, the explicit representation of their permutation reactions would be too demanding in terms of implementation and computational time. A parameterization is required, of the type proposed by Madronich and Calvert (1990) and Jenkin et al. (1997). Following the same approach as in these studies, the $\mathrm{RO}_{2}$ radicals are grouped into classes according to their structure. Each class is characterized by a self-reaction rate (Table 2). The permutation reactions of an explicit $\mathrm{RO}_{2}$ are represented by the reactions of this compound with pseudo-species representing the different classes. The concentration of a pseudo-species is equal to the sum of the explicit peroxy radicals concentrations in the corresponding class. Whenever a particular peroxy radical is produced or destroyed in the mechanism, the pseudo-species representing its class is also produced or destroyed. The rate constant of the reaction between a given $\mathrm{RO}_{2}$ and a class is estimated as twice the geometric average of the self-reaction rate constants $\mathrm{k}_{\mathrm{self}\left(\mathrm{RO}_{2}\right)}$ and $\mathrm{k}_{\text {self(class) }}$ :

$k_{7}=2 \times\left(k_{\text {self }\left(\mathrm{RO}_{2}\right)} \times k_{\text {self(class })}\right)^{1 / 2}$.

An important exception to this rule is the case of the reactions of acyl peroxy radicals with other $\mathrm{RO}_{2}$, as discussed further below. The classes are defined according to the substitutions and chemical functionalities (hydroxy, carbonyl, or allyl), if any, in $\alpha$ or $\beta$ position.

Since the photooxidation of $\alpha$-pinene produces mostly $\mathrm{C}_{\geq 7}$ peroxy radicals, the cross reactions involve mostly large radicals in laboratory conditions. In the atmosphere, the reactions of large $\alpha$-pinene radicals with smaller radicals (e.g. $\mathrm{CH}_{3} \mathrm{O}_{2}$ and radicals from isoprene) might be important as well. However, since our current focus is mainly on laboratory conditions, we limit our classification to large $\left(\mathrm{C}_{\geq 7}\right)$ radicals. The literature data for the self-reaction rates of peroxy radicals are reported in Table 3 . Based on these values, the self-reaction rates adopted for each class are 
Table 3. Self-reaction rates $\left(k_{\text {self }}\right)$ of $\mathrm{RO}_{2}$ radicals measured at $298 \mathrm{~K}$.

\begin{tabular}{|c|c|c|c|c|c|}
\hline $\mathrm{RO}_{2}$ & $k_{\text {self }}$ & Ref. & $\mathrm{RO}_{2}$ & $k_{\text {self }}$ & Ref. \\
\hline Primary alkyl/allyl (R1R) & & & Secondary hydroxy $(R 2 H)$ & & \\
\hline $\mathrm{CH}_{3} \mathrm{O}_{2}$ & $3.7(-13)^{\star}$ & $a$ & $\mathrm{CH}_{3} \mathrm{CH}(\mathrm{OH}) \mathrm{CH}\left(\mathrm{O}_{2}\right) \mathrm{CH}_{3}$ & $6.9(-13)$ & $f$ \\
\hline $\mathrm{C}_{2} \mathrm{H}_{5} \mathrm{O}_{2}$ & $6.6(-14)$ & $a$ & $c-\mathrm{C}_{6} \mathrm{H}_{10}(\mathrm{OH}) \mathrm{O}_{2}$ & $1.6(-12)$ & $j, k$ \\
\hline$n-\mathrm{C}_{3} \mathrm{H}_{7} \mathrm{O}_{2}$ & $3.9(-13)$ & $a$ & & & \\
\hline$n-\mathrm{C}_{5} \mathrm{H}_{11} \mathrm{O}_{2}$ & $3.9(-13)$ & $e$ & Tertiary hydroxy $(R 3 H)$ & & \\
\hline $\mathrm{C}\left(\mathrm{CH}_{3}\right)_{3} \mathrm{CH}_{2} \mathrm{O}_{2}$ & $1.2(-12)$ & $a$ & $\mathrm{C}\left(\mathrm{CH}_{3}\right)_{2}(\mathrm{OH}) \mathrm{C}\left(\mathrm{CH}_{3}\right)_{2} \mathrm{O}_{2}$ & $4.0(-15)$ & $f$ \\
\hline $\mathrm{CH}_{2}=\mathrm{CHCH}_{2} \mathrm{O}_{2}$ & $6.9(-13)$ & $b$ & $\mathrm{C}\left(\mathrm{CH}_{3}\right)_{2} \mathrm{O}_{2} \mathrm{CH}_{2} \mathrm{OH}$ & $1.5(-14)$ & $j$ \\
\hline $\mathrm{CH}_{2}(\mathrm{OH}) \mathrm{CH}=\mathrm{CHCH}_{2} \mathrm{O}_{2}$ & $2.8(-12)$ & $c$ & $c-\mathrm{C}_{6} \mathrm{H}_{8}\left(\mathrm{CH}_{3}\right)_{2}(\mathrm{OH}) \mathrm{O}_{2}$ & $2.0(-14)$ & $j, l$ \\
\hline $\mathrm{CH}_{2}(\mathrm{OH}) \mathrm{C}\left(\mathrm{CH}_{3}\right)=\mathrm{C}\left(\mathrm{CH}_{3}\right) \mathrm{CH}_{2} \mathrm{O}_{2}$ & $3.9(-12)$ & $c$ & & & \\
\hline Secondary alkyl $(R 2 R)$ & & & $\begin{array}{l}\text { Primary } \alpha \text {-hydroxy/ } \alpha \text {-carbonyl/ } \\
\text { multifunctional }(R I M)\end{array}$ & & \\
\hline$i-\mathrm{C}_{3} \mathrm{H}_{7} \mathrm{O}_{2}$ & $1.1(-15)$ & $a$ & $\mathrm{CH}_{2}(\mathrm{OH}) \mathrm{O}_{2}$ & $6.2(-12)$ & $a$ \\
\hline$c-\mathrm{C}_{5} \mathrm{H}_{9} \mathrm{O}_{2}$ & $4.5(-14)$ & $a$ & $\mathrm{CH}_{3} \mathrm{C}(\mathrm{O}) \mathrm{CH}_{2} \mathrm{O}_{2}$ & $8.3(-12)$ & $a$ \\
\hline$c-\mathrm{C}_{6} \mathrm{H}_{11} \mathrm{O}_{2}$ & $4.2(-14)$ & $a$ & & & \\
\hline$s e c-\mathrm{C}_{5} \mathrm{H}_{11} \mathrm{O}_{2}$ & $3.3(-14)$ & $e$ & Secondary $\alpha$-hydroxy $/ \alpha$-carbonyl/ & & \\
\hline$s e c-\mathrm{C}_{10} \mathrm{H}_{21} \mathrm{O}_{2}$ & $9.4(-14)$ & $e$ & multifunctional (R2M) & & \\
\hline$s e c-\mathrm{C}_{12} \mathrm{H}_{25} \mathrm{O}_{2}$ & $1.4(-13)$ & $e$ & $\mathrm{CH}_{2}(\mathrm{OH}) \mathrm{CH}\left(\mathrm{O}_{2}\right) \mathrm{CH}=\mathrm{CH}_{2}$ & $5.7(-12)$ & $c$ \\
\hline $\begin{array}{l}\text { Tertiary alkyl }(\mathrm{R} 3 \mathrm{R}) \\
\left(\mathrm{CH}_{3}\right)_{3} \mathrm{CO}_{2}\end{array}$ & $3.3(-17)$ & $a$ & $\begin{array}{l}\text { Tertiary } \alpha \text {-hydroxy/ } \alpha \text {-carbonyl/ } \\
\text { multifunctional }(R 3 M)\end{array}$ & & \\
\hline Primary hydroxy $(\mathrm{R} 1 \mathrm{H})$ & & & $\mathrm{CH}_{2}(\mathrm{OH}) \mathrm{C}\left(\mathrm{CH}_{3}\right)\left(\mathrm{O}_{2}\right) \mathrm{C}\left(\mathrm{CH}_{3}\right)=\mathrm{CH}_{2}$ & $6.9(-14)$ & $c$ \\
\hline $\mathrm{CH}_{2}(\mathrm{OH}) \mathrm{CH}_{2} \mathrm{O}_{2}$ & $2.3(-12)$ & $f$ & Acyl peroxy radicals (RO3) & & \\
\hline$\left(\mathrm{CH}_{3}\right)_{2} \mathrm{C}(\mathrm{OH}) \mathrm{CH}_{2} \mathrm{O}_{2}$ & $4.8(-12)$ & $g$ & $\begin{array}{l}\mathrm{CH}_{3} \mathrm{C}(\mathrm{O}) \mathrm{O}_{2} \\
\left(\mathrm{CH}_{3}\right)_{2} \mathrm{CHC}(\mathrm{O}) \mathrm{O}_{2} \\
\left(\mathrm{CH}_{3}\right)_{3} \mathrm{CC}(\mathrm{O}) \mathrm{O}_{2}\end{array}$ & $\begin{array}{l}1.6(-11) \\
1.4(-11) \\
1.4(-11)\end{array}$ & $\begin{array}{l}h \\
i \\
i\end{array}$ \\
\hline
\end{tabular}

${ }^{\star}$ Notation is $3.7(-13)=3.7 \times 10^{-13}{ }^{a}$ Lightfoot et al. (1992) ${ }^{b}$ Boyd et al. (1996a) ${ }^{c}$ Jenkin et al. (1998) ${ }^{e}$ Boyd et al. (1999) ${ }^{f}$ Boyd et al. (1997) ${ }^{g}$ Boyd et al. (1996b) ${ }^{h}$ Atkinson et al. (2003) ${ }^{i}$ Tomas and Lesclaux (2000) ${ }^{j}$ Boyd et al. (2003) ${ }^{k} 2$-hydroxycyclohexyl peroxy radical ${ }^{l} 2$-hydroxy-1,2-dimethylcyclohexyl peroxy radical

discussed below. The notations used here for the different classes are as in Table 2.

\section{Alkyl peroxy radicals (R1R, R2R, R3R)}

Experimental data exist for primary alkyl radicals (R1R) of different structures. Lightfoot et al. (1992) and Boyd et al. (1999) measured the self-reaction rate of the linear primary radicals up to $n-\mathrm{C}_{5} \mathrm{H}_{11} \mathrm{O}_{2}$. However, the presence of a double bond or a substitution in $\beta$ in a primary radical appears to increase its $\mathrm{k}_{\text {self }}$ as e.g. for $\mathrm{C}\left(\mathrm{CH}_{3}\right)_{3} \mathrm{CH}_{2} \mathrm{O}_{2}$ and $\mathrm{CH}_{2}(\mathrm{OH}) \mathrm{C}\left(\mathrm{CH}_{3}\right)=\mathrm{C}\left(\mathrm{CH}_{3}\right) \mathrm{CH}_{2} \mathrm{O}_{2}$ (Jenkin et al., 1998). The radicals generated in our mechanism are usually substituted. Therefore we assume that the structure of the neo-pentyl radical $\left(\mathrm{C}\left(\mathrm{CH}_{3}\right)_{3} \mathrm{CH}_{2} \mathrm{O}_{2}\right)$ is representative of the primary peroxy radicals in our model. Since the $\mathrm{k}_{\text {self }}$ for non-linear alkyl radicals increases slightly with carbon number, we set the self-reaction rate to $4.0 \times 10^{-12} \mathrm{~cm}^{3} \mathrm{molec}^{-1} \mathrm{~s}^{-1}$ for the R1R class.

Boyd et al. (1999) parameterized the self-reaction rates of linear secondary alkyl peroxy radicals (R2R) as a function of the carbon number $n$. Based on this relationship, and assuming that this rate is somewhat higher due to the numerous allyl and substituted secondary radicals present in the mechanism, a $\mathrm{k}_{\mathrm{self}}$ of $4.0 \times 10^{-13} \mathrm{~cm}^{3}$ molec $^{-1} \mathrm{~s}^{-1}$ is chosen for the R2R class.

Few data exist for the alkyl tertiary radicals (R3R). Lightfoot et al. (1992) reported a very low value of $\mathrm{k}_{\text {self }}$ for $\left(\mathrm{CH}_{3}\right)_{3} \mathrm{CO}_{2}$. We assume a value of $1.0 \times 10^{-16} \mathrm{~cm}^{-3}$ molec $^{-1} \mathrm{~s}^{-1}$ to represent the R3R class.

\section{$\beta$-hydroxy peroxy radicals ( $\mathrm{R} 1 \mathrm{H}, \mathrm{R} 2 \mathrm{H}, \mathrm{R} 3 \mathrm{H})$}

The measurements performed by Lesclaux and coworkers (Boyd et al., 1996b, 1997, 2003) show that the presence of a $\beta$-hydroxy functionality on the peroxy radical increases significantly the self-reaction rate. On the basis of these experimental values, the $\mathrm{k}_{\text {self }}$ of primary radicals $(\mathrm{R} 1 \mathrm{H}$ class) is extrapolated to $8.0 \times 10^{-12} \mathrm{~cm}^{-3}$ molec $^{-1} \mathrm{~s}^{-1}$ for $\mathrm{R} 1 \mathrm{H}$ radicals generated by the $\alpha$-pinene oxidation. Following the same approach, the self-reaction rates of $\beta$-hydroxy secondary $(\mathrm{R} 2 \mathrm{H})$ and tertiary $(\mathrm{R} 3 \mathrm{H})$ 
radicals are set to $3.0 \times 10^{-12} \mathrm{~cm}^{-3} \mathrm{molec}^{-1} \mathrm{~s}^{-1}$ and $5.0 \times 10^{-14} \mathrm{~cm}^{-3} \mathrm{molec}^{-1} \mathrm{~s}^{-1}$, respectively. Boyd et al. (2003) measured the cross reaction rate between a R2H and a $\mathrm{R} 3 \mathrm{H} C_{7}$ radical. Using Eq. (3) with our estimated self-reaction rates, we calculate a cross reaction rate in fair agreement with their experimental data of $6.2 \times 10^{-13} \mathrm{~cm}^{-3} \mathrm{molec}^{-1} \mathrm{~s}^{-1}$.

\section{$\alpha$-hydroxy/ $\beta$-carbonyl/multifunctional peroxy radicals (R1M, R2M, R3M)}

Measurements of self-reaction rates for $\alpha$-hydroxy and $\beta$-carbonyl substituted primary alkyl peroxy radicals show high rate values (Lightfoot et al., 1992). A value of $1.5 \times 10^{-11} \mathrm{~cm}^{3} \mathrm{molec}^{-1} \mathrm{~s}^{-1}$ is chosen for this class (R1M). In absence of more measurement data, we consider this rate as an overall upper limit for the peroxy radicals $\mathrm{k}_{\text {self }}$, and compounds containing more than one functionality among hydroxy, carbonyl and allyl substitutions in $\alpha$ or in $\beta$ are also included in this class. Based on the measurements of Jenkin et al. (1998), rates of $1.0 \times 10^{-11}$ and $1.0 \times 10^{-13} \mathrm{~cm}^{-3} \mathrm{molec}^{-1} \mathrm{~s}^{-1}$ are used for the corresponding secondary (R2M) and tertiary (R3M) classes, respectively.

\section{Acyl peroxy radicals (RO3)}

Experimental evidence indicates that the cross reaction rates of acyl peroxy radicals (RO3) with all the other peroxy radicals are of the same order of magnitude $\left(1-1.25 \times 10^{-11} \mathrm{~cm}^{3} \mathrm{molec}^{-1} \mathrm{~s}^{-1}\right.$ ) (Villenave and Lesclaux, 1998; Atkinson et al., 2003). A value of $1 \times 10^{-11} \mathrm{~cm}^{3} \mathrm{molec}^{-1} \mathrm{~s}^{-1}$ is adopted for these reactions. The rate of the pseudo-reaction between an acyl peroxy radical and the RO3 class is set to $1.5 \times 10^{-11} \mathrm{~cm}^{3} \mathrm{molec}^{-1} \mathrm{~s}^{-1}$, based on the measurement of the self-reaction rate constant of $\left(\mathrm{CH}_{3}\right)_{3} \mathrm{CC}(\mathrm{O}) \mathrm{O}_{2}$ (Tomas and Lesclaux, 2000).

2.3 "Exotic" peroxy radical reactions in the oxidation of $\alpha$-pinene

As described in Peeters et al. (2001), the reaction of a large secondary (or tertiary) $\alpha$-hydroxyalkyl radical with $\mathrm{O}_{2}$ produces an activated peroxy radical $\mathrm{RCH}(\mathrm{OH}) \mathrm{O}_{2}{ }^{\dagger}$ (or $\left.\mathrm{R}^{\prime} \mathrm{C}(\mathrm{OH}) \mathrm{O}_{2} \mathrm{R}^{\dagger}\right)$. The activated peroxy radical can either stabilize collisionally or decompose thermally in competing reactions. In the case of $\mathrm{RCH}(\mathrm{OH}) \mathrm{O}_{2}^{\dagger}$ :

$\mathrm{RCH}(\mathrm{OH}) \mathrm{O}_{2}^{\dagger} \rightarrow \mathrm{RCHO}+\mathrm{HO}_{2}$

$\mathrm{RCH}(\mathrm{OH}) \mathrm{O}_{2}^{\dagger} \rightarrow \mathrm{RCH}(\mathrm{OH}) \mathrm{O}_{2}$.

Using a detailed RRKM-Master Equation (ME) analysis based on high-level G2M quantum chemical data. Hermans et al., (2004) ${ }^{1}$ estimated the prompt decomposition rates for the nascent chemically activated $\mathrm{HOCH}_{2} \mathrm{O}_{2}{ }^{\dagger}$, $\mathrm{CH}_{3} \mathrm{CH}(\mathrm{OH}) \mathrm{O}_{2}^{\dagger}$ and $\mathrm{C}\left(\mathrm{CH}_{3}\right)_{2}(\mathrm{OH}) \mathrm{O}_{2}^{\dagger}$ to be on the order of $10^{10} \mathrm{~s}^{-1}$, and their effective stabilization rates were found to lie in the range $10^{4}-10^{-1} \mathrm{~s}^{-1}$. These results are in agreement with the available experimental data. For the much larger radicals involved in the oxidation of $\alpha$-pinene, prompt decomposition and stabilization rates should be more competitive. Using RRKM-ME, we estimate the ratio $\mathrm{k}_{R 8 \mathrm{a}} / \mathrm{k}_{R 8 \mathrm{~b}}$ to be about $10 / 90$ and $25 / 75$ in the cases of $\mathrm{R}_{13} \mathrm{O}_{2}^{\dagger}$ and $\mathrm{R}_{3} \mathrm{O}_{2}^{\dagger}$ (Fig. 1), respectively. The probable error on these ratios is a factor of 2.5. The stabilized $\alpha$-hydroxyalkyl peroxy radical $\mathrm{RCH}(\mathrm{OH}) \mathrm{O}_{2}$ can either decompose or be oxidized via the traditional reactions with $\mathrm{NO}, \mathrm{HO}_{2}$ and $\mathrm{RO}_{2}$ radicals as described in Sect. 2.2. In presence of NO, two reactions compete with each other:

$$
\begin{aligned}
& \mathrm{RCH}(\mathrm{OH}) \mathrm{O}_{2} \rightarrow \mathrm{RCHO}+\mathrm{HO}_{2} \\
& \mathrm{RCH}(\mathrm{OH}) \mathrm{O}_{2}+\mathrm{NO} \rightarrow \mathrm{RCH}(\mathrm{OH}) \mathrm{O}+\mathrm{NO}_{2} .
\end{aligned}
$$

The $\alpha$-hydroxyalkoxy radical produced in the reaction (R10) decomposes, producing $\mathrm{HCOOH}$ (or $\mathrm{R}^{\prime} \mathrm{C}(\mathrm{O}) \mathrm{OH}$ in the case of the decomposition of the tertiary $\left.\mathrm{RC}(\mathrm{OH}) \mathrm{O}_{2} \mathrm{R}^{\prime \dagger}\right)$ :

$\mathrm{RCH}(\mathrm{OH}) \mathrm{O} \rightarrow \mathrm{R}+\mathrm{HCOOH}$.

The rate of the thermal decomposition Reaction (R9) is strongly dependent on the degree of substitution of the alpha-hydroxy peroxy radical. Hermans et al. (2004) ${ }^{1}$ estimated the decomposition rates of $\mathrm{HOCH}_{2} \mathrm{O}_{2}$ (primary), $\mathrm{CH}_{3} \mathrm{CH}(\mathrm{OH}) \mathrm{O}_{2}$ (secondary) and $\mathrm{C}\left(\mathrm{CH}_{3}\right)_{2}(\mathrm{OH}) \mathrm{O}_{2}$ (tertiary) to $201 \mathrm{~s}^{-1}, 2710 \mathrm{~s}^{-1}$ and $29300 \mathrm{~s}^{-1}$ at $300 \mathrm{~K}$, respectively. These results are in good agreement with the available experimental data, although the measured decomposition rate of $\mathrm{CH}_{3} \mathrm{CH}(\mathrm{OH}) \mathrm{O}_{2}$ is somewhat lower $\left(1870 \mathrm{~s}^{-1}\right.$ at $\left.298 \mathrm{~K}\right)$ than the theoretical estimate by Hermans et al. (2004) ${ }^{1}$. In the case of $\mathrm{R}_{13} \mathrm{O}_{2}$ and $\mathrm{R}_{3} \mathrm{O}_{2}$, the fairly strong $\mathrm{H}$-bond that can result between the hydroxyl-H and the carbonyl-O should slow down the decomposition somewhat, but as this bond is entropically disfavored, this should reduce the thermal decomposition rate $\mathrm{k}_{R}$ by only a factor of 1.5 . For $\mathrm{R}_{13} \mathrm{O}_{2}$, we adopt the experimental value of $1870 \mathrm{~s}^{-1}$ for secondary radicals, but reduced by a factor of 1.5 , i.e. $\mathrm{k}_{R 9}=1250 \mathrm{~s}^{-1}$. For $\mathrm{R}_{3} \mathrm{O}_{2}$, given the absence of experimental data for the tertiary case, we adopt the estimate by Hermans et al. (2004) ${ }^{1}$ again reduced for the hydroxyl-to-aldehyde hydrogen bonding, setting $\mathrm{k}_{R}$ to $1.9 \times 10^{4} \mathrm{~s}^{-1}$ at $298 \mathrm{~K}$. Since $\mathrm{HCOOH}$ is mainly produced from Reaction (11) in our mechanism, the laboratory measurement of the formic acid yield by Orlando et al. $(2000)\left(7 \%\right.$ yield for $[\mathrm{NO}]=2-22 \times 10^{14}$ molecule $\left./ \mathrm{cm}^{3}\right)$ partly validates the rates adopted here for $\mathrm{R}_{13} \mathrm{O}_{2}^{\dagger}$ and $\mathrm{R}_{13} \mathrm{O}_{2}$. The yield estimated from our mechanism ranges from $\sim 2 \%$ at $2 \mathrm{ppm}$ to $16 \%$ at $20 \mathrm{ppm} \mathrm{NO}$. The statistical average over the $2-20 \mathrm{ppm}$ range is $\sim 10 \%$, i.e. reasonably close to the measurement. Reaction (R10) involving $\mathrm{R}_{13} \mathrm{O}_{2}$ competes with (R9) for $\mathrm{NO} \gg 100 \mathrm{ppb}$. Because of the faster decomposition rate of $\mathrm{R}_{3} \mathrm{O}_{2}$, its reaction with $\mathrm{NO}$ becomes effective for $\mathrm{NO} \gg 5 \mathrm{ppm}$. Under these conditions, the overall product yields in the $\alpha$-pinene oxidation are dependent on the concentration of NO. In particular, the yields of pinonaldehyde 
and acetone are determined by the fate of the radicals $\mathrm{R}_{3} \mathrm{O}_{2}$ and $\mathrm{R}_{13} \mathrm{O}_{2}$ (Fig. 1).

Vereecken and Peeters (2004) demonstrated the importance of ring-closure reactions of unsaturated oxy and peroxy radicals formed in the atmospheric oxidation of biogenic NMOCs. They showed in particular that the radical $\mathrm{R}_{7} \mathrm{O}_{2}$ formed in the $\alpha$-pinene oxidation mechanism undergoes a ring closure reaction with a rate of $\sim 2.5 \mathrm{~s}^{-1}$. The primary production of acetone generated subsequent to the competing reactions of $\mathrm{R}_{7} \mathrm{O}_{2}$ is therefore also dependent on the level of NO. It should be noted that the chemistry following the ring closure remains so far unknown. A discussion of the influence of these specific reactions on the yield of pinonaldehyde and acetone is given in Sect. 3.6.

\subsection{Chemistry of the primary products}

The $\mathrm{OH}$-oxidation rates of the first generation products in the degradation of $\alpha$-pinene can be estimated using the structurereactivity approach (SAR) proposed by Kwok et al. (1995). The estimated rates for the compounds present in the mechanism range from $1 \times 10^{-12}$ to $7 \times 10^{-11} \mathrm{~cm}^{3}$ molec $^{-1} \mathrm{~s}^{-1}$ according to the structure of the compound considered. The estimation of their photolysis rate is described in the next section. There are no published degradation mechanism for these compounds, to the exception of pinonaldehyde. A detailed investigation of such degradation mechanisms would be beyond the scope of the present study. A simplified representation is therefore adopted. Our aim is to represent the main impact of the oxidation of primary products, i.e. the generation of a chain of peroxy radicals reactions which, in high $\mathrm{NO}$ conditions, contribute to $\mathrm{NO}$ to $\mathrm{NO}_{2}$ conversion and to nitrate production. We assume here that the unknown chemistry of primary products proceeds in ways similar to the explicit mechanism. Based on this similarity assumption, we estimate to about 4 the average number of successive peroxy radical reactions necessary to generate a stable compound from the oxidation of a typical $\left(\mathrm{C}_{9}\right.$ or $\mathrm{C}_{10}$ ) product in high $\mathrm{NO}_{\mathrm{x}}$ conditions, about half of which are $\mathrm{C}_{\geq 7}$ peroxy radical reactions. Due to the marked dependence of the nitrate yield on the size of the peroxy radicals in $\mathrm{RO}_{2}+\mathrm{NO}$ reactions, it is found useful to distinguish between large $\left(\mathrm{C}_{\geq 7}\right)$ peroxy radicals produced from the oxidation of primary products, noted $\mathrm{LXO} 2$, and smaller $\left(\mathrm{C}_{<7}\right)$ radicals, noted SXO2.

Based on these observations, the oxidation of $\mathrm{C}_{\geq 7}$ products is represented as a unique reaction producing generic peroxy radicals:

$\mathrm{C}_{\geq 7}$ product $+\mathrm{OH} \rightarrow \lambda \sum_{i=1}^{n} \alpha_{i} \mathrm{LXO}_{i}$,

$\mathrm{LXO}_{i}$ is a generic peroxy radical $\mathrm{C}_{\geq 7}$ of class $i$, as defined in Table 2. $\lambda$ represents the assumed average number of oxidation steps necessary to obtain a radical of carbon number lower than 7 and is taken equal to 2 . The distribution of the generic peroxy radicals among the different classes are defined by the stoichiometric coefficients $\alpha_{i}$. It is assumed to be similar to the distribution of the different peroxy radicals classes present in the explicit mechanism. The sum of the $\alpha_{i}$ of the different classes $i$ is equal to unity. Based on a simple count of the number of peroxy radicals in each class in the $\alpha$-pinene+OH mechanism, the " $\mathrm{RxH}$ " and "RxM" $(\mathrm{x}=1,2$ or 3 ) classes are found to be dominant. The distribution is parameterized as follows: $\alpha_{\mathrm{RxR}}=0.06, \alpha_{\mathrm{RxH}}=0.1, \alpha_{\mathrm{RxM}}=0.1$, $\alpha_{\mathrm{RO} 3}=0.2$.

These $\mathrm{LXO} 2$ radicals react with $\mathrm{NO}, \mathrm{HO}_{2}$ and the other $\mathrm{RO}_{2}$ radicals, producing stable products and smaller $\left(\mathrm{C}_{<7}\right)$ generic peroxy radicals $\mathrm{SXO} 2$ :

$$
\begin{aligned}
& \mathrm{LXO}_{\mathrm{i}}+\mathrm{NO} \rightarrow \mathrm{NO}_{2}+\sum_{i=1}^{n} \alpha_{i} \mathrm{SXO}_{\mathrm{i}} \\
& \mathrm{LXO}_{\mathrm{i}}+\mathrm{NO} \rightarrow \mathrm{LXONO}_{2} \\
& \mathrm{LXO}_{\mathrm{i}}+\mathrm{HO}_{2} \rightarrow \mathrm{LXOOH}^{2} \mathrm{O}_{2} \\
& \mathrm{LXO}_{2}+\mathrm{RO}_{2} \rightarrow a \sum_{i=1}^{n} \alpha_{i} \mathrm{SXO} 2_{\mathrm{i}}+b \mathrm{LXOH}+c \mathrm{LXCHO} .
\end{aligned}
$$

The SXO2 radicals react in the same manner and terminate the propagation chain:

$$
\begin{aligned}
& \mathrm{SXO}_{2}+\mathrm{NO} \rightarrow \mathrm{NO}_{2} \\
& \mathrm{SXO}_{2}+\mathrm{NO} \rightarrow \mathrm{SXONO}_{2} \\
& \mathrm{SXO}_{2}+\mathrm{HO}_{2} \rightarrow \mathrm{SXOOH}+\mathrm{O}_{2} \\
& \mathrm{SXO}_{2}+\mathrm{RO}_{2} \rightarrow b \mathrm{SXOH}+c \mathrm{SXCHO} .
\end{aligned}
$$

The coefficients $a, b$ and $c$ in (R15) and (R18) depend on the structure of the radicals $\mathrm{LXO}_{2}$ and $\mathrm{SXO} 2_{\mathrm{i}}$ (see Table 1).

The $\mathrm{C}_{<7}$ primary products are treated as their $\mathrm{C}_{\geq 7}$ counterparts:

$\mathrm{C}_{<7}$ products $+\mathrm{OH} \rightarrow \lambda \sum_{i=1}^{n} \alpha_{i} \mathrm{SXO} 2_{\mathrm{i}}$.

The coefficients $\lambda$ and $\alpha_{i}$ in Eq. (R19) are assumed to be the same as in Eq. (R12).

The subsequent reactions of radicals for which the chemistry is still speculative are also treated following Eq. (R12) or (R19) according to the carbon number of the radical considered. For example, in the case of the $\mathrm{R}_{11}$ radical (Fig. 1), we write:

$\mathrm{R}_{11} \rightarrow 2 \sum_{i=1}^{n} \alpha_{i} \mathrm{LXO}_{\mathrm{i}}$.

\subsection{Photolysis}

Photochemistry in most NMOC photooxidation experiments is initiated by the photodissociation of an $\mathrm{OH}$ precursor, which is either $\mathrm{H}_{2} \mathrm{O}_{2}$ :

$\mathrm{H}_{2} \mathrm{O}_{2}+h v \rightarrow 2 \mathrm{OH}$ 


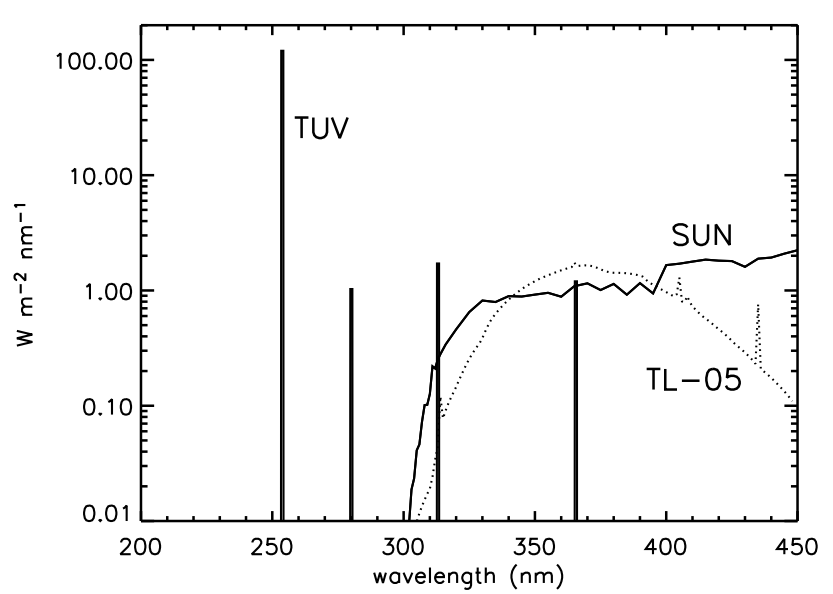

Fig. 3. Actinic fluxes of the TUV and TL-05 lamps used in N99. A solar spectrum (ground level, standard atmosphere, zenith angle $=45^{\circ}$ ) is also shown for comparison (solid line).

or $\mathrm{CH}_{3} \mathrm{ONO}$ :

$$
\begin{aligned}
\mathrm{CH}_{3} \mathrm{ONO}+h v & \rightarrow \mathrm{CH}_{3} \mathrm{O}+\mathrm{NO} \\
\mathrm{CH}_{3} \mathrm{O}+\mathrm{O}_{2} & \rightarrow \mathrm{CH}_{2} \mathrm{O}+\mathrm{HO}_{2} \\
\mathrm{NO}+\mathrm{HO}_{2} & \rightarrow \mathrm{NO}_{2}+\mathrm{OH} .
\end{aligned}
$$

In the $\mathrm{N} 99$ experiments, $\mathrm{H}_{2} \mathrm{O}_{2}$ is photolysed by TUV mercury lamps emitting short-wave ultraviolet radiation with a concentrated radiation peak at $253.7 \mathrm{~nm}$. In the second case, TL-05 mercury lamps (Philips, $\lambda_{\max }=360 \mathrm{~nm}$ ) are used. The lamp spectra are shown in Fig. 3 as well as the solar spectrum at ground level. The intensity of the lamps reported in the figure are those estimated for the N99 experiments. Because the TL-05 lamps radiate mostly in the $300-480 \mathrm{~nm}$ range, they are often considered more appropriate to represent solar radiation in real tropospheric conditions. The experiments performed using TL-05 and TUV lamps will hereafter be referred as "visible" and "UV" experiments, respectively.

The photodissociation coefficient (J-value) for a given photolytic process $i$ is calculated as

$J_{i}=\int_{\lambda} I(\lambda) \times \sigma_{i}(\lambda) \times \phi_{i}(\lambda) \times d \lambda$

where $\lambda$ is the wavelength, $I(\lambda)$ is the average actinic flux in the reactor, $\sigma_{i}(\lambda)$ and $\phi_{i}(\lambda)$ are the absorption cross section and the photolysis quantum yield of the species $i$, respectively. The actinic flux $I(\lambda)$ is not directly measured, but it can be related to measurable quantities by writing,

$I(\lambda)=I_{0} \times f(\lambda)$

where $f(\lambda)$ is either the TUV or TL-05 normalized lamp

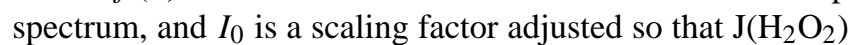
or $\mathrm{J}\left(\mathrm{CH}_{3} \mathrm{ONO}\right)$ calculated using Eq. (4) matches the observed decay rate of $\mathrm{H}_{2} \mathrm{O}_{2}$ or $\mathrm{CH}_{3} \mathrm{ONO}$ in the reactor. The following average photolysis rates are deduced from the

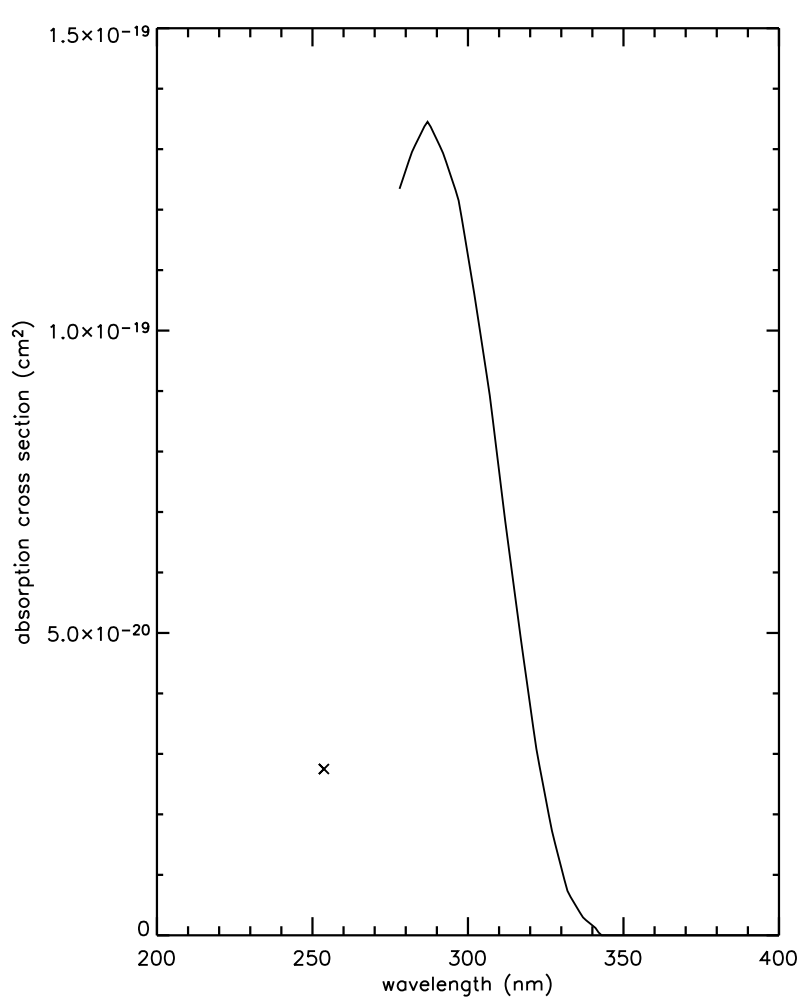

Fig. 4. Pinonaldehyde absorption cross sections from Hallquist et al. (1997) (solid line). The value at $253.7 \mathrm{~nm}$ (cross) is estimated in this study.

observations of $\mathrm{H}_{2} \mathrm{O}_{2}$ and $\mathrm{CH}_{3} \mathrm{ONO}$ in the $\mathrm{N} 99$ experiments:

$\mathrm{J}\left(\mathrm{H}_{2} \mathrm{O}_{2}\right)=1.0 \times 10^{-3} s^{-1}$
$\mathrm{~J}\left(\mathrm{CH}_{3} \mathrm{ONO}\right)=9.1 \times 10^{-4} s^{-1}$.

These values are corrected for minor effects due to secondary reactions influencing $\mathrm{CH}_{3} \mathrm{ONO}$ and $\mathrm{H}_{2} \mathrm{O}_{2}$. The derivation of $I_{0}$ is straightforward, because the photolytic parameters for both precursors are well known.

Equation (4) has been used to derive J-values for inorganic compounds as well as for the carbonyls, organic nitrates, peroxy acyl nitrates and hydroperoxides produced in the photooxidation of $\alpha$-pinene. The photolysis of alcohols and carboxylic acids are not considered, since they are expected to be slow. The photodissociation processes for which the absorption cross sections and the quantum yields are known from laboratory studies are listed in Table 4. The corresponding J-values were calculated for both the UV and visible experiments in N99. In addition, the J-values estimated for typical tropospheric conditions using the TUV photolysis calculation model of Madronich and Flocke (1998) are also shown for comparison.

The photolysis parameters for other compounds which have not been directly investigated in the laboratory have 
Table 4. Photolysis reactions for which the photodissociation parameters ( $\sigma=$ cross section, $\phi=$ quantum yield) are known from laboratory investigations, and estimated J-values in the N99 reactors and in typical tropospheric conditions (ground level, standard atmosphere, zenith angle $=45^{\circ}$ ).

\begin{tabular}{|c|c|c|c|c|}
\hline Reactions & $\begin{array}{c}\mathrm{J}\left(s^{-1}\right) \\
\mathrm{TUV}\end{array}$ & $\begin{array}{c}\mathrm{J}\left(s^{-1}\right) \\
\text { TL-05 }\end{array}$ & $\begin{array}{l}\mathrm{J}\left(s^{-1}\right) \\
\text { Tropos. }\end{array}$ & Notes \\
\hline $\mathrm{O}_{3}+\mathrm{h} v \rightarrow \mathrm{O}\left({ }^{1} \mathrm{D}\right)+\mathrm{O}_{2}$ & $1.6(-1)^{\star}$ & $4.0(-6)$ & $1.7(-5)$ & $a, b$ \\
\hline $\mathrm{O}_{3}+\mathrm{h} v \rightarrow \mathrm{O}+\mathrm{O}_{2}$ & $2.2(-1)$ & $9.7(-6)$ & $1.4(-5)$ & $a, b$ \\
\hline $\mathrm{NO}_{3}+\mathrm{h} v \rightarrow \mathrm{NO}_{2}+\mathrm{O}$ & 0. & $4.0(-4)$ & $1.7(-1)$ & $\mathrm{c}, \mathrm{d}$ \\
\hline $\mathrm{NO}_{3}+\mathrm{h} v \rightarrow \mathrm{NO}+\mathrm{O}_{2}$ & 0. & 0. & $2.2(-2)$ & $\mathrm{c}, \mathrm{d}$ \\
\hline $\mathrm{NO}_{2}+\mathrm{h} v \rightarrow \mathrm{NO}+\mathrm{O}$ & $3.7(-4)$ & $9.2(-3)$ & $8.2(-3)$ & $\mathrm{c}$ \\
\hline $\mathrm{N}_{2} \mathrm{O}_{5}+\mathrm{h} v \rightarrow \mathrm{NO}_{3}+\mathrm{NO}+\mathrm{O}$ & $3.2(-3)$ & 0. & $4.1(-10)$ & c \\
\hline $\mathrm{N}_{2} \mathrm{O}_{5}+\mathrm{h} v \rightarrow \mathrm{NO}_{3}+\mathrm{NO}_{2}$ & $1.3(-3)$ & $1.6(-5)$ & $2.8(-5)$ & $\mathrm{c}$ \\
\hline $\mathrm{H}_{2} \mathrm{O}_{2}+\mathrm{h} v \rightarrow \mathrm{OH}+\mathrm{OH}$ & $1.0(-3)$ & $2.7(-6)$ & $5.1(-6)$ & c \\
\hline $\mathrm{HONO}+\mathrm{h} v \rightarrow \mathrm{OH}+\mathrm{NO}$ & $2.2(-3)$ & $1.8(-3)$ & $1.4(-3)$ & c \\
\hline $\mathrm{HNO}_{3}+\mathrm{h} v \rightarrow \mathrm{OH}+\mathrm{NO}_{2}$ & $3.0(-4)$ & $1.3(-7)$ & $4.1(-7)$ & $\mathrm{c}$ \\
\hline $\mathrm{HNO}_{4}+\mathrm{h} v \rightarrow \mathrm{HO}_{2}+\mathrm{NO}_{2}$ & $3.3(-3)$ & $1.2(-6)$ & $2.8(-6)$ & $\mathrm{c}, \mathrm{e}$ \\
\hline $\mathrm{HNO}_{4}+\mathrm{h} v \rightarrow \mathrm{OH}+\mathrm{NO}_{3}$ & $2.3(-3)$ & $8.6(-7)$ & $1.9(-6)$ & $\mathrm{c}, \mathrm{e}$ \\
\hline $\mathrm{CH}_{2} \mathrm{O}+\mathrm{h} v \rightarrow \mathrm{CO}+2 \mathrm{HO}_{2}$ & $2.0(-5)$ & $9.7(-6)$ & $2.8(-5)$ & $\mathrm{c}$ \\
\hline $\mathrm{CH}_{2} \mathrm{O}+\mathrm{h} v \rightarrow \mathrm{H}_{2}+\mathrm{CO}$ & $2.7(-5)$ & $3.0(-5)$ & $3.8(-5)$ & $\mathrm{c}$ \\
\hline $\mathrm{CH}_{3} \mathrm{CHO}+\mathrm{h} v \rightarrow \mathrm{CH}_{3} \mathrm{O}_{2}+\mathrm{HO}_{2}+\mathrm{CO}$ & $5.5(-5)$ & $7.7(-7)$ & $3.2(-6)$ & $\mathrm{c}$ \\
\hline $\mathrm{CH}_{3} \mathrm{CHO}+\mathrm{h} v \rightarrow \mathrm{CH}_{4}+\mathrm{CO}$ & $1.4(-4)$ & 0. & $3.0(-11)$ & $\mathrm{c}$ \\
\hline $\mathrm{CH}_{3} \mathrm{OOH}+\mathrm{h} v \rightarrow \mathrm{CH}_{3} \mathrm{O}+\mathrm{OH}$ & $5.3(-4)$ & $2.5(-6)$ & $4.1(-6)$ & $\mathrm{c}$ \\
\hline $\mathrm{CHOCHO}+\mathrm{h} v \rightarrow 0.09 \mathrm{CH}_{2} \mathrm{O}+1.6 \mathrm{CO}+0.6 \mathrm{H}_{2}+0.31 \mathrm{HO}_{2}+0.31 \mathrm{OH}$ & $7.1(-5)$ & $1.5(-5)$ & $6.9(-5)$ & $\mathrm{c}$ \\
\hline $\mathrm{CH}_{3} \mathrm{COCH}_{3}+\mathrm{h} v \rightarrow \mathrm{CH}_{3} \mathrm{CO}_{3}+\mathrm{CH}_{3} \mathrm{O}_{2}$ & $4.4(-4)$ & $9.4(-8)$ & $3.6(-7)$ & $\mathrm{f}$ \\
\hline $\mathrm{CH}_{3} \mathrm{COC}_{2} \mathrm{H}_{5}+\mathrm{h} v \rightarrow \mathrm{CH}_{3} \mathrm{CO}+\mathrm{C}_{2} \mathrm{H}_{5}$ & $5.1(-4)$ & $1.4(-7)$ & $5.8(-7)$ & $\mathrm{c}, \mathrm{g}$ \\
\hline $\mathrm{CH}_{2} \mathrm{OHCHO}+\mathrm{h} v \rightarrow \mathrm{CH}_{3} \mathrm{OH}+\mathrm{CO}$ & $2.7(-4)$ & 0. & $2.8(-11)$ & $\mathrm{c}, \mathrm{h}$ \\
\hline $\mathrm{CH}_{2} \mathrm{OHCHO}+\mathrm{h} v \rightarrow \mathrm{CH}_{2} \mathrm{O}+2 \mathrm{OH}+\mathrm{CO}$ & $1.3(-4)$ & $3.9(-7)$ & $1.7(-6)$ & $\mathrm{c}, \mathrm{h}$ \\
\hline $\mathrm{CH}_{3} \mathrm{C}(\mathrm{O}) \mathrm{CHO}+\mathrm{h} v \rightarrow \mathrm{CH}_{3} \mathrm{CO}_{3}+\mathrm{CO}+\mathrm{HO}_{2}$ & $4.4(-4)$ & $3.9(-4)$ & $6.5(-4)$ & $\mathrm{c}$ \\
\hline $\mathrm{CH}_{2}=\mathrm{CHC}(\mathrm{O}) \mathrm{CH}_{3}+\mathrm{h} v \rightarrow \mathrm{CH}_{2}=\mathrm{CHCO}_{3}+\mathrm{CH}_{3} \mathrm{O}_{2}$ & $0.8(-5)$ & $0.4(-6)$ & $0.7(-6)$ & $\mathrm{c}, \mathrm{i}$ \\
\hline $\mathrm{CH}_{2}=\mathrm{CHC}(\mathrm{O}) \mathrm{CH}_{3}+\mathrm{h} v \rightarrow \mathrm{CH}_{2}=\mathrm{CHCH}_{3}+\mathrm{CO}$ & $2.5(-5)$ & $1.2(-6)$ & $2.0(-6)$ & $\mathrm{c}, \mathrm{i}$ \\
\hline $\mathrm{CH}_{2}=\mathrm{CHC}(\mathrm{O}) \mathrm{CH}_{3}+\mathrm{h} v \rightarrow \mathrm{CH}_{3} \mathrm{CO}_{3}+\mathrm{CH}_{2} \mathrm{O}+\mathrm{CO}$ & $0.8(-5)$ & $0.4(-6)$ & $0.7(-6)$ & $\mathrm{c}, \mathrm{i}$ \\
\hline \multicolumn{5}{|l|}{$\mathrm{CH}_{2}=\mathrm{C}\left(\mathrm{CH}_{3}\right) \mathrm{CHO}+\mathrm{h} v \rightarrow 0.5 \mathrm{CH}_{2}=\mathrm{C}\left(\mathrm{CH}_{3}\right)+0.5 \mathrm{HCO}$} \\
\hline$+0.5 \mathrm{CH}_{2}=\mathrm{CH}\left(\mathrm{CH}_{3}\right)+0.5 \mathrm{CO}$ & $2.4(-6)$ & $2.1(-5)$ & $2.1(-5)$ & $\mathrm{c}, \mathrm{i}$ \\
\hline \multicolumn{5}{|l|}{$\mathrm{CH}_{2}=\mathrm{CHCHO}+\mathrm{h} v \rightarrow 0.5 \mathrm{CH}_{2}=\mathrm{CH}+0.5 \mathrm{HCO}$} \\
\hline$+0.5 \mathrm{CH}_{2}=\mathrm{CH}_{2}+0.5 \mathrm{CO}$ & $4.8(-7)$ & $1.9(-6)$ & $2.0(-6)$ & $\mathrm{i}, \mathrm{j}$ \\
\hline $\mathrm{CH}_{3} \mathrm{ONO}_{2}+\mathrm{h} v \rightarrow \mathrm{CH}_{3} \mathrm{O}+\mathrm{NO}_{2}$ & $5.2(-4)$ & $1.8(-7)$ & $5.8(-7)$ & $\mathrm{k}$ \\
\hline $\mathrm{CH}_{3} \mathrm{C}(\mathrm{O}) \mathrm{CH}_{2} \mathrm{ONO}_{2}+\mathrm{h} v \rightarrow \mathrm{CH}_{3} \mathrm{C}(\mathrm{O}) \mathrm{CH}_{2} \mathrm{O}+\mathrm{NO}_{2}$ & $2.1(-3)$ & $8.5(-6)$ & $2.5(-5)$ & $1, \mathrm{~m}$ \\
\hline $\mathrm{CH}_{3} \mathrm{ONO}+\mathrm{h} v \rightarrow \mathrm{CH}_{3} \mathrm{O}+\mathrm{NO}$ & $5.3(-5)$ & $9.1(-4)$ & $1.2(-3)$ & $\mathrm{n}$ \\
\hline $\mathrm{CH}_{3} \mathrm{C}(\mathrm{O}) \mathrm{O}_{2} \mathrm{NO}_{2}+\mathrm{h} v \rightarrow \mathrm{CH}_{3} \mathrm{C}(\mathrm{O}) \mathrm{O}_{2}+\mathrm{NO}_{2}$ & $1.3(-3)$ & $1.9(-7)$ & $4.1(-7)$ & c \\
\hline $\mathrm{CH}_{3} \mathrm{C}(\mathrm{O}) \mathrm{O}_{2} \mathrm{NO}_{2}+\mathrm{h} v \rightarrow \mathrm{CH}_{3} \mathrm{C}(\mathrm{O}) \mathrm{O}+\mathrm{NO}_{3}$ & $0.3(-3)$ & $0.4(-7)$ & $1.0(-7)$ & $\mathrm{c}$ \\
\hline
\end{tabular}

$\star$ Notation is $1.6(-1)=1.6 \times 10^{-1} a^{a}$ Sander et al. (2000) ${ }^{b}$ Molina and Molina (1999) ${ }^{c}$ Atkinson et al. (2003) $d$ Johnston et al. (1996) $e^{\star}$ Knight et al. (1900) $f$ Gierczak et al. (1998) and Warneck (2001) $g$ quantum yield assumed equal to the wavelength-dependent quantum yields of acetone multiplied by a factor 1.2, in order to match the averaged yield measured by Raber et al. (1995) $h$ assumed equal to the wavelength-dependent quantum yields of $\mathrm{CH}_{3} \mathrm{CHO}$ for the different photodissociation paths, adjusted to match the averaged yield reported by Bacher et al. (2001) ${ }^{i}$ Raber et al. (1995) ${ }^{j}$ Gardner et al. (1987) ${ }^{k}$ Talukdar et al. (2001) ${ }^{l}$ Barnes et al. (1993) ${ }^{m}$ assumed equal to one ${ }^{n}$ Hippler et al. (1992)

been estimated based on assumed simple relationships between the photolytic parameters of compounds of similar structures. Table 5 summarizes the reactions and rates for the species of interest in this study. The reference species on which the estimations are based are also indicated in the table. Pinonaldehyde and organic nitrates are important special cases and will be discussed in the next sections.

\subsubsection{Pinonaldehyde}

The absorption cross sections of pinonaldehyde have been measured by Hallquist et al. (1997) between 275 and $345 \mathrm{~nm}$ (Fig. 4). Being a keto-aldehyde, it can be expected to photolyse following both aldehydic and ketone dissociation channels. In the first case, by analogy with other aldehydes like 
Table 5. Photolysis reactions for the species and classes considered in this work, and estimated rates in the N99 reactors and in typical tropospheric conditions (ground level, standard atmosphere, zenith angle $=45^{\circ}$ ).

\begin{tabular}{|c|c|c|c|c|}
\hline Reaction & $\begin{array}{c}\mathrm{J}\left(s^{-1}\right) \\
\mathrm{TUV}\end{array}$ & $\begin{array}{c}\mathrm{J}\left(s^{-1}\right) \\
\mathrm{TL}-05\end{array}$ & $\begin{array}{c}\mathrm{J}\left(s^{-1}\right) \\
\text { Troposphere }\end{array}$ & $\begin{array}{l}\text { Reference } \\
\text { species }\end{array}$ \\
\hline PINALD $+\mathrm{h} v \rightarrow \mathrm{R}_{17}+\mathrm{CHO}$ & $2.4(-5)$ & $2.2(-6)$ & $6.9(-6)$ & see text \\
\hline PINALD $+\mathrm{h} v \rightarrow 0.5 \mathrm{CH}_{2}=\mathrm{CHC}(\mathrm{O}) \mathrm{CH}_{3}+0.5 \mathrm{C}\left(\mathrm{CH}_{3}\right)_{2}=\mathrm{CHCH}_{2} \mathrm{CHO}$ & $3.3(-5)$ & $3.0(-6)$ & $0.9(-5)$ & see text \\
\hline PINALD $+\mathrm{h} v \rightarrow 0.5 \mathrm{CH}_{2}=\mathrm{CHCH}_{2} \mathrm{CHO}+0.5 \mathrm{CH}_{3} \mathrm{C}(\mathrm{O}) \mathrm{CH}=\mathrm{C}\left(\mathrm{CH}_{3}\right)_{2}$ & $3.3(-5)$ & $3.0(-6)$ & $0.9(-5)$ & see text \\
\hline $\mathrm{PINALD}+\mathrm{h} v \rightarrow \mathrm{R}_{4}+\mathrm{CH}_{3} \mathrm{CO}$ & $2.4(-4)$ & $9.4(-7)$ & $3.4(-6)$ & see text \\
\hline Keto-aldehydes $\mathrm{C}_{<7}+\mathrm{h} v \rightarrow$ products & $4.4(-4)$ & $3.9(-4)$ & $6.5(-4)$ & Methyl glyoxa \\
\hline Keto-aldehydes $\mathrm{C}_{\geq 7}+\mathrm{h} v \rightarrow$ products & $3.3(-4)$ & $9.2(-6)$ & $2.9(-5)$ & PINALD \\
\hline Aldehydes $+\mathrm{h} v \rightarrow$ products & $8.2(-5)$ & $5.4(-6)$ & $1.5(-5)$ & Pentanal \\
\hline di-aldehydes $+\mathrm{h} v \rightarrow$ products & $7.1(-5)$ & $1.5(-5)$ & $6.9(-5)$ & Glyoxal \\
\hline $\mathrm{RC}(\mathrm{O}) \mathrm{R}^{\prime}+\mathrm{h} v \rightarrow \mathrm{RC}(\mathrm{O}) \mathrm{O}_{2}$ & $5.1(-4)$ & $1.4(-7)$ & $5.8(-7)$ & MEK \\
\hline $\mathrm{ROOH}+\mathrm{h} v \rightarrow$ products & $5.3(-4)$ & $2.5(-6)$ & $4.1(-6)$ & $\mathrm{CH}_{3} \mathrm{OOH}$ \\
\hline Unsaturated ketones $+\mathrm{h} v \rightarrow$ products & $4.1(-5)$ & $1.9(-6)$ & $3.4(-6)$ & MVK \\
\hline Unsaturated aldehydes $+\mathrm{h} v \rightarrow$ products & $2.4(-6)$ & $2.1(-5)$ & $2.1(-5)$ & MACR \\
\hline Nitrates $\mathrm{C}_{<7}+\mathrm{h} v \rightarrow \mathrm{RO}+\mathrm{NO}_{2}$ & $9.0(-4)$ & $1.3(-6)$ & $4.5(-6)$ & see text \\
\hline Nitrates $\mathrm{C}_{\geq 7}+\mathrm{h} v \rightarrow \mathrm{RO}+\mathrm{NO}_{2}$ & $1.3(-3)$ & $2.7(-6)$ & $1.1(-5)$ & see text \\
\hline Keto-nitrates $\mathrm{C}_{<7}+\mathrm{h} v \rightarrow \mathrm{RO}+\mathrm{NO}_{2}$ & $2.7(-3)$ & $1.3(-5)$ & $3.6(-5)$ & see text \\
\hline Keto-nitrates $\mathrm{C}_{\geq 7}+\mathrm{h} v \rightarrow \mathrm{RO}+\mathrm{NO}_{2}$ & $4.0(-3)$ & $2.5(-5)$ & $6.3(-5)$ & see text \\
\hline $\mathrm{RC}(\mathrm{O}) \mathrm{O}_{2} \mathrm{NO}_{2}+\mathrm{h} v \rightarrow \mathrm{RC}(\mathrm{O}) \mathrm{O}_{2}+\mathrm{NO}_{2}$ & $1.3(-3)$ & $1.9(-7)$ & $4.1(-7)$ & PAN \\
\hline $\mathrm{RC}(\mathrm{O}) \mathrm{O}_{2} \mathrm{NO}_{2}+\mathrm{h} v \rightarrow \mathrm{RC}(\mathrm{O}) \mathrm{O}+\mathrm{NO}_{3}$ & $0.3(-3)$ & $0.4(-7)$ & $1.0(-7)$ & PAN \\
\hline
\end{tabular}

$n$-pentanal (Tadic et al., 2001a) and $n$-hexanal (Tadic et al., 2001b), intramolecular rearrangements and fragmentations into free radicals take place. One radical channel (R25a) (Norrish-Type I) and two molecular channels (R25b) and (R25c) (Norrish-Type II) can be considered (PINALD stands for pinonaldehyde):

$$
\begin{aligned}
\text { PINALD }+h v \rightarrow & \mathrm{CHO}+\mathrm{R}_{17} \\
\text { PINALD }+h v \rightarrow & \mathrm{CH}_{2}=\mathrm{CHC}(\mathrm{O}) \mathrm{CH}_{3}+ \\
& \mathrm{CH}_{3} \mathrm{C}\left(\mathrm{CH}_{3}\right)=\mathrm{CHCH}_{2} \mathrm{CHO} \\
\text { PINALD }+h v \rightarrow & \mathrm{CH}_{3} \mathrm{C}(\mathrm{O}) \mathrm{CH}=\mathrm{C}\left(\mathrm{CH}_{3}\right) \mathrm{CH}_{3}+ \\
& \mathrm{CH}_{2}=\mathrm{CHCH}_{2} \mathrm{CHO} .
\end{aligned}
$$

The molecular channels are assumed to proceed through two energetically favored symmetric cleavages of the strained four-membered ring. In absence of experimental data, the two resulting molecular channels are assumed to have the same probability.

The ketone dissociation channel can be assumed to proceed by cleavage of the $\mathrm{CH}_{3} \mathrm{CO}-\mathrm{R}$ bond of pinonaldehyde, based on the example of methyl ethyl ketone (Atkinson et al., 2003):

PINALD $+h v \rightarrow \mathrm{R}_{4}+\mathrm{CH}_{3} \mathrm{CO}$.

Tadic et al. (2001a, b, 2002) measured the relative importance of the different photolysis channels of aldehydes. Their experiments between 275 and $380 \mathrm{~nm}$ showed that the contribution of the molecular channel increases slowly with chain length: $70 \%$ for $n$-pentanal, $73 \%$ for $n$-hexanal and $80 \%$ for $n$-heptanal. The average quantum yields (averages weighted by the lamp spectrum and the absorption cross sections) were measured to be $0.32,0.34,0.38$ and 0.31 at 700 Torr for $\mathrm{C}_{4}-\mathrm{C}_{7}$ alkanals. They all show a similar dependence on total pressure. It should be noted however, that Desai et al. (1986) and Atkinson et al. (2003) reported substantially higher quantum yields for propanal and isobutanal. Based on these studies, we calculate average quantum yields of 0.70 and 0.66 for these two species, respectively (averages weighted by their respective absorption cross sections (Atkinson et al., 2003) and by the spectrum of the lamp used in Tadic et al.). The origins of this difference are unclear.

We assume here that the averaged quantum yield of nhexanal $(0.38)$ can be used for the aldehydic channels of pinonaldehyde, with probabilities of $27 \%$ and $73 \%$ for the Norrish-Type I and II, respectively. These yields are assumed to be essentially independent on wavelength. The wavelength-dependent quantum yields of methyl ethyl ketone (MEK) is used for the ketone photodissociation channel. Below $290 \mathrm{~nm}$, the quantum yields are scaled down so that the total quantum yield does not exceed 1 .

The estimated pinonaldehyde quantum yields are shown in Table 6. It can be seen that the ketone dissociation channel is expected to be dominant in the UV experiments, while the aldehydic channels are expected to prevail in the visible experiments.

By using the cross sections of Hallquist et al. (1997) with the quantum yields and the lamp spectrum in Eq. (4) described above, a rate of $9.2 \times 10^{-6} \mathrm{~s}^{-1}$ is calculated for the visible experiments, i.e. less than the measurement $\left(5.5 \times 10^{-5} \mathrm{~s}^{-1}\right)$ based on a blank pinonaldehyde experiment 
Table 6. Estimated pinonaldehyde photolysis quantum yields. $\phi_{1}$, $\phi_{2}$ and $\phi_{3}$ represent the aldehyde Norrish I, Norrish II and ketone photolysis pathways, respectively.

\begin{tabular}{ccccc}
\hline wavelength / nm & $\phi_{1}$ & $\phi_{2}$ & $\phi_{3}$ & $\phi_{\text {total }}$ \\
\hline 250 & 0.07 & 0.20 & 0.72 & 1.0 \\
280 & 0.09 & 0.23 & 0.68 & 1.0 \\
290 & 0.10 & 0.28 & 0.52 & 0.9 \\
300 & 0.10 & 0.28 & 0.26 & 0.64 \\
310 & 0.10 & 0.28 & 0.10 & 0.48 \\
320 & 0.10 & 0.28 & 0.04 & 0.42 \\
330 & 0.10 & 0.28 & 0.02 & 0.40 \\
340 & 0.10 & 0.28 & 0.01 & 0.39 \\
\hline
\end{tabular}

conducted in the absence of $\mathrm{CH}_{3} \mathrm{ONO}$ by N99. Such a discrepancy between the experimental and theoretical J-values cannot be attributed to uncertainties in the pinonaldehyde photolysis parameters. Indeed, even the maximum theoretical quantum yield (unity) would result in a J-value lower than the measured value. In any case, both experimental and theoretical values are very low, making pinonaldehyde photolysis almost negligible in the visible experiments.

A similar estimation of the J-value using Eq. (4) is not possible for the UV experiments, because the cross sections are unknown at or around the lamp emission peak $(253.7 \mathrm{~nm})$. Therefore, the measured photolytic rate of $3.3 \times 10^{-4} \mathrm{~s}^{-1}$ reported in N99 for the UV experiments is used in our model. Combining this value with the TUV lamp spectrum, we estimate the cross section of pinonaldehyde to about $2.8 \times 10^{-20} \mathrm{~cm}^{2}$ at $253.7 \mathrm{~nm}$ (Fig. 4).

\subsubsection{Alkyl nitrates}

The absorption cross sections of organic alkyl nitrates are based on the recommendations of Atkinson et al. (2003). The quantum yield is assumed equal to 1 throughout the visible and UV spectrum. The only channel considered is:

$\mathrm{RONO}_{2}+h v \rightarrow \mathrm{RO}+\mathrm{NO}_{2}$.

The calculated photodissociation rates of several organic nitrates investigated in the laboratory are listed in Table 7. The rates are seen to increase with the number of carbons. They are also higher when a ketone functionality is present. The increase of $\mathrm{J}(n$-alkyl nitrates) with carbon number obeys roughly a logarithmic law. The rate depends also on the position of the nitrate group, as illustrated by the differences between isopropyl nitrate $\left(i-\mathrm{CH}_{3} \mathrm{CH}\left(\mathrm{ONO}_{2}\right) \mathrm{CH}_{3}\right)$, 2-butyl nitrate $\left(\mathrm{CH}_{3} \mathrm{CH}_{2} \mathrm{CH}\left(\mathrm{ONO}_{2}\right) \mathrm{CH}_{3}\right)$ and their n-alkyl counterparts. We group the numerous nitrates generated in the $\alpha$ pinene photooxidation into 4 families: $\mathrm{C}_{<7}$ alkyl nitrates, $\mathrm{C}_{\geq 7}$ alkyl nitrates, $\mathrm{C}_{<7}$ keto-nitrates and $\mathrm{C}_{\geq 7}$ keto-nitrates. The rate of 2-butyl nitrate is adopted for the $\mathrm{C}_{<7}$ alkyl nitrates. Barnes et al. (1993) reported absorption cross sections of $\alpha$-nitrooxy acetone, 1-nitrooxy-2-butanone and 3-
Table 7. Photolysis rates of several alkyl nitrates under the UV and visible conditions in N99.

\begin{tabular}{|c|c|c|}
\hline Species & $\begin{array}{c}\mathrm{J}\left(s^{-1}\right) \\
\mathrm{TUV}\end{array}$ & $\begin{array}{l}\mathrm{J}\left(s^{-1}\right) \\
\mathrm{TL}-05\end{array}$ \\
\hline \multicolumn{3}{|l|}{ n-alkyl nitrates } \\
\hline $\mathrm{CH}_{3} \mathrm{ONO}_{2}{ }^{a}$ & $5.2 \times 10^{-4}$ & $1.8 \times 10^{-7}$ \\
\hline $\mathrm{CH}_{3} \mathrm{CH}_{2} \mathrm{ONO}_{2}{ }^{a}$ & $6.2 \times 10^{-4}$ & $3.1 \times 10^{-7}$ \\
\hline$n-\mathrm{C}_{3} \mathrm{H}_{7} \mathrm{ONO}_{2}{ }^{a}$ & $6.9 \times 10^{-4}$ & $4.6 \times 10^{-7}$ \\
\hline$n-\mathrm{C}_{4} \mathrm{H}_{9} \mathrm{ONO}_{2}{ }^{a}$ & $7.4 \times 10^{-4}$ & $4.4 \times 10^{-7}$ \\
\hline \multicolumn{3}{|l|}{ alkyl nitrates } \\
\hline$i-\mathrm{CH}_{3} \mathrm{CH}\left(\mathrm{ONO}_{2}\right) \mathrm{CH}_{3}{ }^{a}$ & $7.9 \times 10^{-4}$ & $6.3 \times 10^{-7}$ \\
\hline $\begin{array}{l}\mathrm{CH}_{3} \mathrm{CH}_{2} \mathrm{CH}\left(\mathrm{ONO}_{2}\right) \mathrm{CH}_{3}{ }^{a} \\
\text { keto-nitrates }\end{array}$ & $9.0 \times 10^{-4}$ & $1.2 \times 10^{-6}$ \\
\hline $\mathrm{CH}_{3} \mathrm{C}(\mathrm{O}) \mathrm{CH}_{2}\left(\mathrm{ONO}_{2}\right)^{b}$ & $2.1 \times 10^{-3}$ & $8.5 \times 10^{-6}$ \\
\hline $\mathrm{CH}_{3} \mathrm{CH}_{2} \mathrm{C}(\mathrm{O}) \mathrm{CH}_{2}\left(\mathrm{ONO}_{2}\right)^{b}$ & $3.0 \times 10^{-3}$ & $4.3 \times 10^{-6}$ \\
\hline $\mathrm{CH}_{3} \mathrm{CH}\left(\mathrm{ONO}_{2}\right) \mathrm{C}(\mathrm{O}) \mathrm{CH}_{3} b$ & $2.7 \times 10^{-3}$ & $1.2 \times 10^{-5}$ \\
\hline
\end{tabular}

References for the absorption cross sections: ${ }^{a}$ Atkinson et al. (2003). ${ }^{b}$ Barnes et al. (1993)

nitrooxy-2-butanone. The photolysis rate of 3-nitrooxy-2butanone $\left(\mathrm{CH}_{3} \mathrm{CH}\left(\mathrm{ONO}_{2}\right) \mathrm{C}(\mathrm{O}) \mathrm{CH}_{3}\right)$ is assumed to be representative for the $\mathrm{C}_{<7}$ keto-nitrates. The photodissociation rates for $\mathrm{C}_{\geq 7}$ alkyl and keto-nitrates compounds are obtained by logarithmic extrapolation. Because of the presence of the carbonyl chromophore in the keto-nitrates, the photolytic cleavage of the $\mathrm{RCO}-\mathrm{CH}\left(\mathrm{ONO}_{2}\right) \mathrm{R}$ bond is another possible pathway for these compounds, in particular in the UV experiments. However, the rupture of the $\mathrm{O}-\mathrm{NO}_{2}$ bond probably dominates. Due to the lack of data, aldehyde-nitrates are assume to photolyse in the same fashion as keto-nitrates.

\section{Results: Mechanism testing and validation with labo- ratory studies}

\subsection{Description of the box model and experiments}

The full mechanism (about 1500 reactions) described in the previous section has been implemented in a box model. In addition, the losses of the stable products on the walls of the reactor were also taken into account based on the loss rate of pinonaldehyde measured in $\mathrm{N} 99\left(4.3 \times 10^{-5} \mathrm{~s}^{-1}\right)$. The same rate is applied to all stable products. The box model solves the continuity equations for the $\sim 600$ chemical species involved in this mechanism. The solver used in this study uses an embedded Rosenbrock scheme of order 4 (Hairer and Wanner, 1990). The FORTRAN code is generated by a preprocessor KPP (Damian-Iordache et al., 1995) which reads text files listing the chemical equations and the species involved in the mechanism.

N99 performed $\alpha$-pinene+OH experiments with and without NO. In presence of NO, 9 experiments were conducted under UV light and 11 experiments under visible light with 
Table 8. Experimental vs modelled yields of products for the photooxidation of alpha-pinene by OH, expressed as percentages of $\alpha$ pinene reacted. The numbers given in the table are averages taken over all experiments in each category $\left(\right.$ high $\mathrm{NO}_{\mathrm{x}} / \mathrm{UV}$, high $\mathrm{NO}_{\mathrm{x}} / \mathrm{visible}$, $\mathrm{NO}_{\mathrm{x}}$-free). The standard deviations around these means are also given.

\begin{tabular}{|c|c|c|c|c|c|c|c|}
\hline & \multirow{2}{*}{$\alpha$-pinene+OH } & \multicolumn{2}{|c|}{ High $\mathrm{NO}_{\mathrm{x}} / \mathrm{UV}$} & \multicolumn{2}{|c|}{ High $\mathrm{NO}_{\mathrm{x}} /$ Visible } & \multicolumn{2}{|c|}{$\mathrm{NO}_{\mathrm{x}}$ Free/UV } \\
\hline & & Model & Exp. & Model & Exp. & Model & Exp \\
\hline \multirow{4}{*}{ Pinonaldehyde } & Primary yield $(Y)$ & $56 \pm 1$ & $(70 \pm 12)^{a}$ & $55 \pm 1$ & $(66 \pm 18)^{a}$ & $26.4 \pm 0.4$ & $(37 \pm 7)^{a}$ \\
\hline & Loss by $\mathrm{h} v(\bar{L})$ & $4 \pm 1$ & & 0. & & $1.7 \pm 0.5$ & \\
\hline & Loss by $\mathrm{OH}(\bar{L})$ & $9 \pm 1$ & & $8 \pm 2$ & & $4.3 \pm 0.7$ & \\
\hline & Apparent yield $\left(\bar{Y}_{\text {app }}\right)$ & $44 \pm 3$ & $44 \pm 8$ & $47 \pm 2$ & $45 \pm 9$ & $20.4 \pm 0.6$ & $21 \pm 1$ \\
\hline \multirow{5}{*}{ Acetone } & Primary yield & $11.1 \pm 0.5$ & $(11 \pm 8)^{a}$ & $11.0 \pm 0.2$ & $(8 \pm 7)^{a}$ & $0.37 \pm 0.05$ & $(6.4 \pm 2)^{a}$ \\
\hline & Secondary yield $\left(\bar{Y}_{s e c}\right)$ & $3.1 \pm 0.9$ & & $1.4 \pm 0.2$ & & $0.13 \pm 0.05$ & \\
\hline & Loss by $h v$ & $1.6 \pm 0.7$ & & 0. & & 0 & \\
\hline & Loss by $\mathrm{OH}$ & 0. & & 0. & & 0 . & \\
\hline & Apparent yield & $12.7 \pm 0.7$ & $12 \pm 5$ & $11.2 \pm 0.1$ & $24 \pm 14$ & $0.47 \pm 0.05$ & $11 \pm 1^{b}$ \\
\hline \multirow{5}{*}{ Formaldehyde } & Primary yield & $12.6 \pm 0.4$ & $(23 \pm 9)^{a}$ & & & $0.5 \pm 0.5$ & $(8.1 \pm 1.2)^{a}$ \\
\hline & Secondary prod. & $9 \pm 2$ & & & & $2.0 \pm 0.5$ & \\
\hline & Loss by $h v$ & $0.3 \pm 0.2$ & & & & 0. & \\
\hline & Loss by $\mathrm{OH}$ & $1.0 \pm 0.2$ & & & & $0.2 \pm 0.1$ & \\
\hline & Apparent yield & $22 \pm 4$ & $56 \pm 25$ & & & $2.6 \pm 0.5$ & $7 \pm 3$ \\
\hline \multirow{5}{*}{$\sum$ Nitrates } & Primary yield & $14.1 \pm 0.4$ & $(26)^{a}$ & $14.5 \pm 0.5$ & $(17 \pm 5)^{a}$ & & \\
\hline & Secondary yield & $2.2 \pm 0.5$ & & $2.0 \pm 0.5$ & & & \\
\hline & Loss by $\mathrm{h} v$ & $5 \pm 1$ & & 0. & & & \\
\hline & Loss by OH & $1.7 \pm 0.3$ & & $1.9 \pm 0.5$ & & & \\
\hline & Apparent Yield & $9 \pm 2$ & 13 & $16.3 \pm 0.5$ & $19 \pm 8$ & & \\
\hline \multirow{5}{*}{$\sum$ PANs } & Loss by $\mathrm{h} v$ & $2 \pm 1$ & & 0 & & & \\
\hline & Loss by OH & $0.23 \pm 0.07$ & & $0.15 \pm 0.10$ & & & \\
\hline & Apparent Yield & $5 \pm 2$ & $5 \pm 2$ & $7 \pm 2$ & $6 \pm 2$ & & \\
\hline & \multirow{2}{*}{ Pinonaldehyde $+\mathrm{OH}$} & \multicolumn{2}{|c|}{ High $\mathrm{NO}_{\mathrm{x}} / \mathrm{UV}$} & \multicolumn{2}{|c|}{ High $\mathrm{NO}_{\mathrm{x}} /$ Visible } & & \\
\hline & & Model & Exp. & Model & Exp. & & \\
\hline \multirow{4}{*}{ Acetone } & Primary yield $^{c}$ & 10 & $(12)^{a}$ & $9.0 \pm 0.0$ & $(20 \pm 6)$ & & \\
\hline & Loss by $\mathrm{h} \nu^{d}$ & 2 & & 0. & & & \\
\hline & Loss by $\mathrm{OH}^{d}$ & 0 & & 0. & & & \\
\hline & Apparent yield ${ }^{d}$ & 20 & 19 & $9.6 \pm 0.1$ & $35 \pm 2$ & & \\
\hline \multirow{4}{*}{ Formaldehyde } & Primary yield ${ }^{c}$ & 29 & $(157)^{a}$ & & & & \\
\hline & Loss by $\mathrm{h} \nu^{d}$ & 1 & & & & & \\
\hline & Loss by $\mathrm{OH}^{d}$ & 2 & & & & & \\
\hline & Apparent yield ${ }^{d}$ & 51 & 167 & & & & \\
\hline \multirow{3}{*}{$\sum$ PANs } & Loss by $\mathrm{h} v^{d}$ & 0.3 & & 0. & & & \\
\hline & Loss by $\mathrm{OH}^{d}$ & 2.2 & & $1.8 \pm 0.2$ & & & \\
\hline & Apparent Yield ${ }^{d}$ & 6.0 & 7.5 & $11.1 \pm 0.6$ & $10.4 \pm 0.7$ & & \\
\hline
\end{tabular}

${ }^{a}$ As reported by N99 ${ }^{b}$ yields calculated for a conversion from 60 to $90 \%$ and with respect to the measured concentration of alphapinene ${ }^{c}$ excluding the production from pinonaldehyde photolysis $d$ including the production from pinonaldehyde photolysis, and calculated using Eq.(6).

$\mathrm{H}_{2} \mathrm{O}_{2}$ and $\mathrm{CH}_{3} \mathrm{ONO}$ as radical precursor, respectively. A few pinonaldehyde $+\mathrm{OH}$ experiments were also carried out in presence of NO. A selection of experiments presenting typical features will be discussed in this study. In the following discussion, the experiments are numbered following their appearance number in Table 1 ( $\alpha$-pinene+OH in presence of NO: Experiments 1 to 21), Table 3 (in absence of NO: Experiments 22 to 31 ) and Table 4 (pinonaldehyde $+\mathrm{OH}$ : Experiments 32 to 37 ) in N99. 
(a)
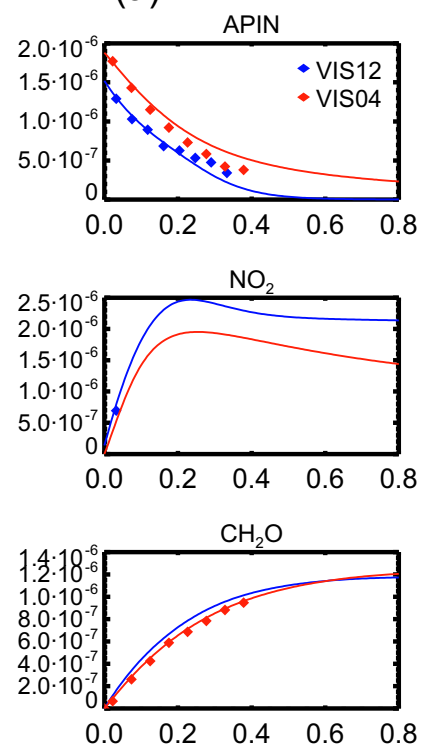

(b)
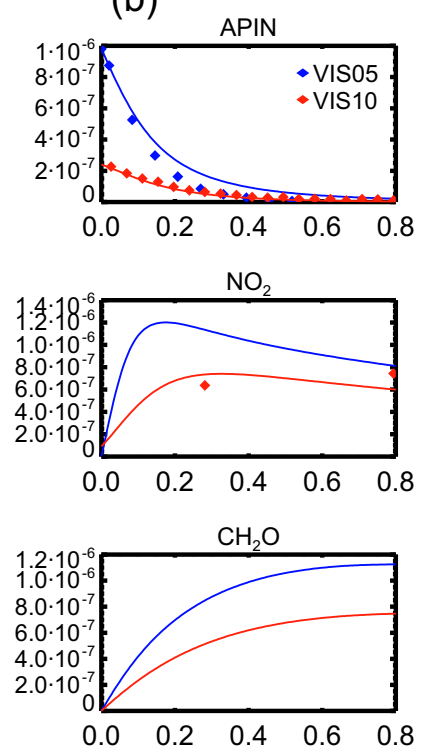
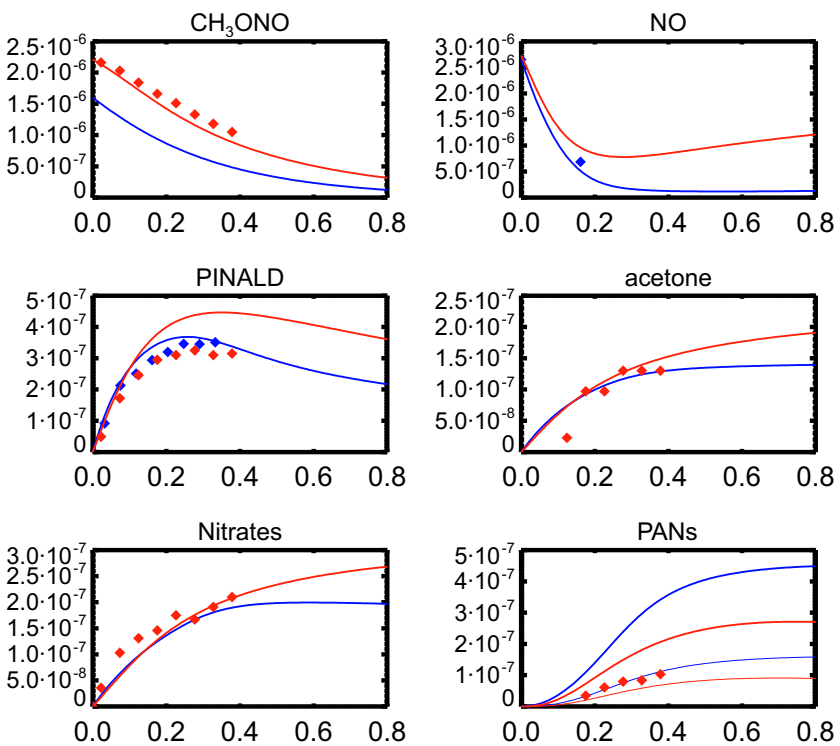

음
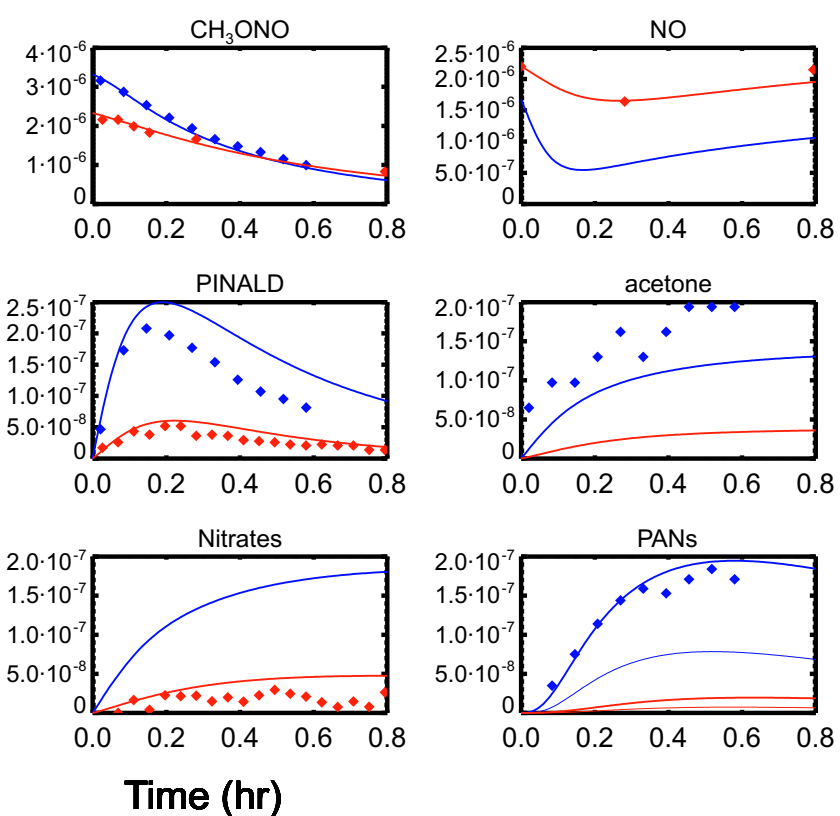

Fig. 5. Measured (diamonds) vs simulated (curves) concentrations as a function of time for several experiments of $\alpha$-pinene oxidation in visible conditions in the presence of $\mathrm{NO}_{\mathrm{x}}$ : (a) Experiments 12 and 4, (b) Experiments 5 and 10 from N99. Two curves are shown for each experiment in the modelled $\Sigma$ PANs: The lowest curve represents the sum of PAN and $\alpha$-PPAN as calculated by the model and the upper curve is the sum of all PANs ( $\sum$ PANs).

The time concentrations of the chemical compounds in the reactor were measured with a Fourier transform infrared (FTIR) spectrometer. The species measured include $\alpha$-pinene, the $\mathrm{OH}$ precursor, pinonaldehyde, acetone and formaldehyde. In addition, organic nitrates, acyl peroxy nitrates (PANs), $\mathrm{NO}$ and $\mathrm{NO}_{2}$ were also estimated in some experiments. For a detailed description of the experiments, we refer to N99.

\subsection{Methodology for comparison}

A simple way to validate the mechanism is to compare the primary product yields deduced from the mechanism with the corresponding yields estimated from the laboratory data. However, the derivation of primary yields from laboratory data is particularly difficult due to the product losses and to the existence of secondary productions. The effect of these 
(a)
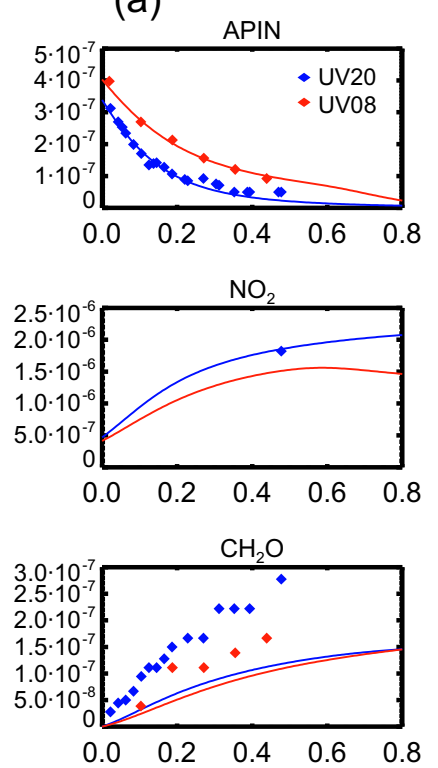

(b)
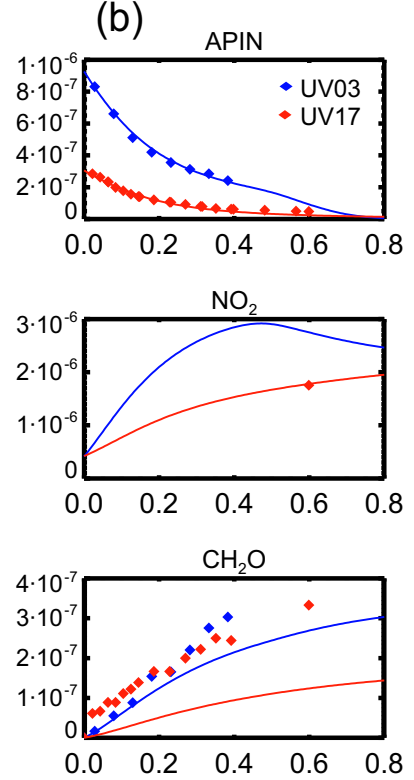
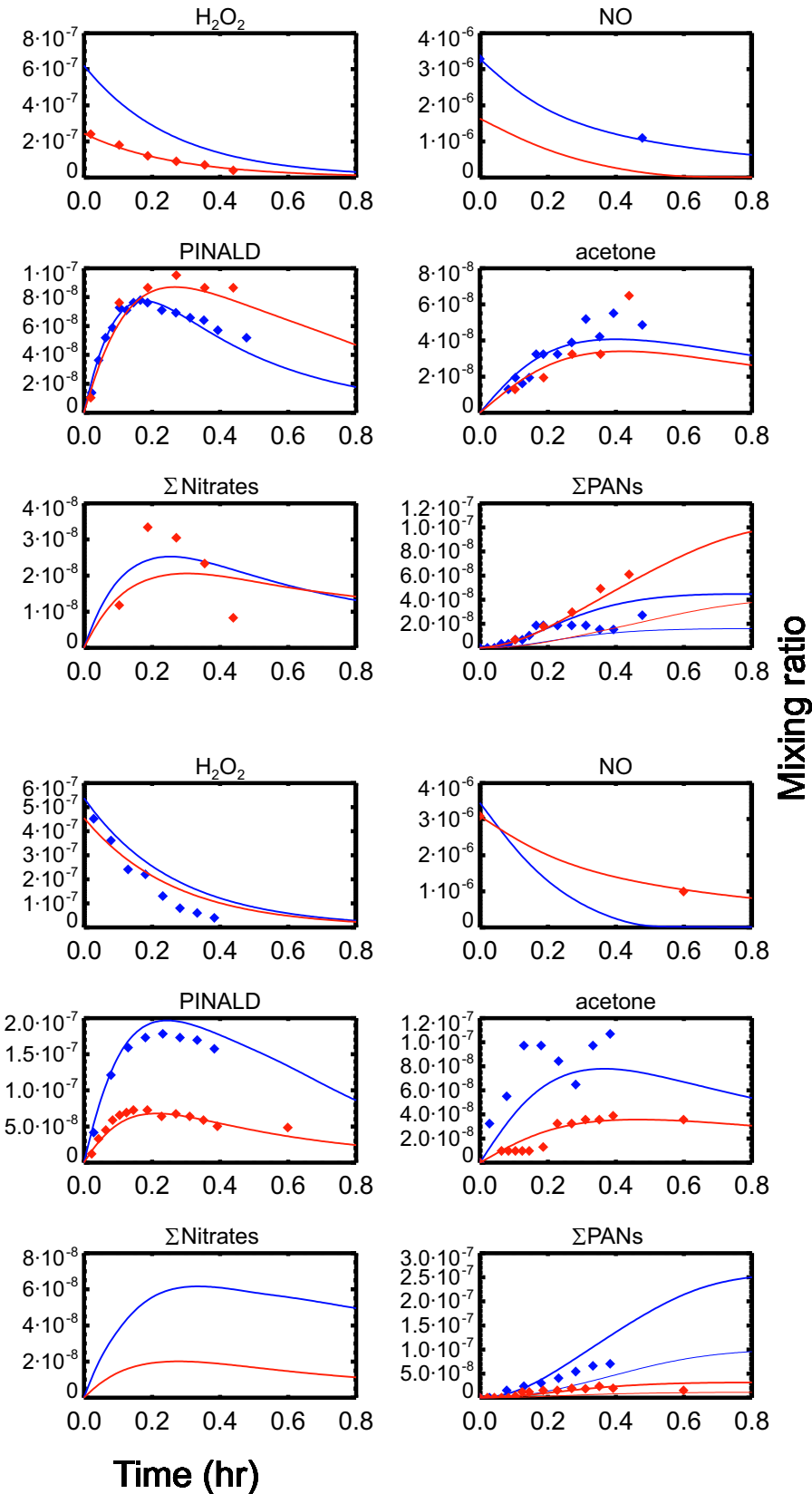

Time (hr)

Fig. 6. Measured (diamonds) vs simulated (curves) concentrations as a function of time for several experiments of $\alpha$-pinene oxidation in UV conditions in the presence of $\mathrm{NO}_{\mathrm{x}}$ : (a) Experiments 20 and 8, (b) Experiments 3 and 17 from N99. Two curves are shown for each experiment in the modelled $\sum$ PANs: The lowest curve represents the sum of PAN and $\alpha$-PPAN as calculated by the model and the upper curve is the sum of all PANs ( $\sum$ PANs).

processes can be minimized by using the concentrations measured in the early stages of the experiment, and by using the fact that the true primary yield can be approximated as

$$
Y(\mathrm{X})=\lim _{t \rightarrow 0} Y_{\mathrm{app}}(\mathrm{X}, t)
$$

where

$$
Y_{\text {app }}(\mathrm{X}, t)=[\mathrm{X}(t)] /([\operatorname{REACTANT}(0)]-[\operatorname{REACTANT}(t)]) .
$$

$Y_{\text {app }}(\mathrm{X}, t)$ is the apparent yield of the product $\mathrm{X}$ at time $t$, and $[\mathrm{X}(t)]$ and $[\operatorname{REACTANT}(t)]$ represent the concentration 
(a)
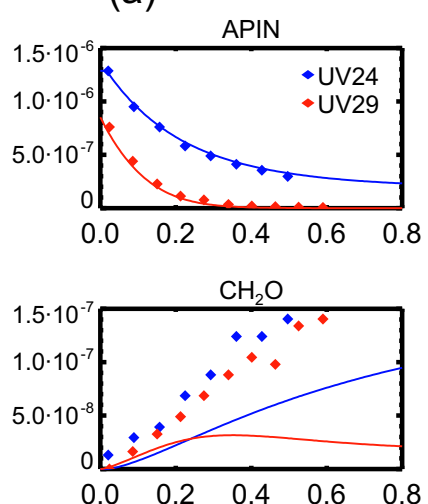

(b)
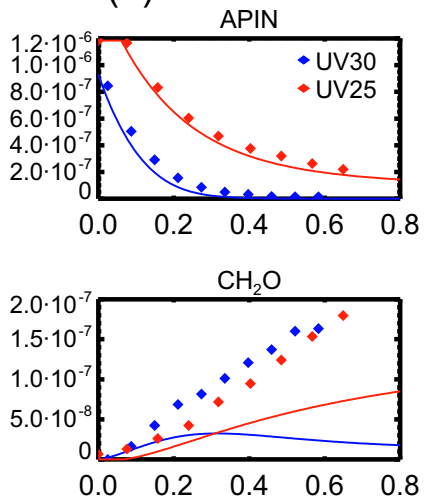
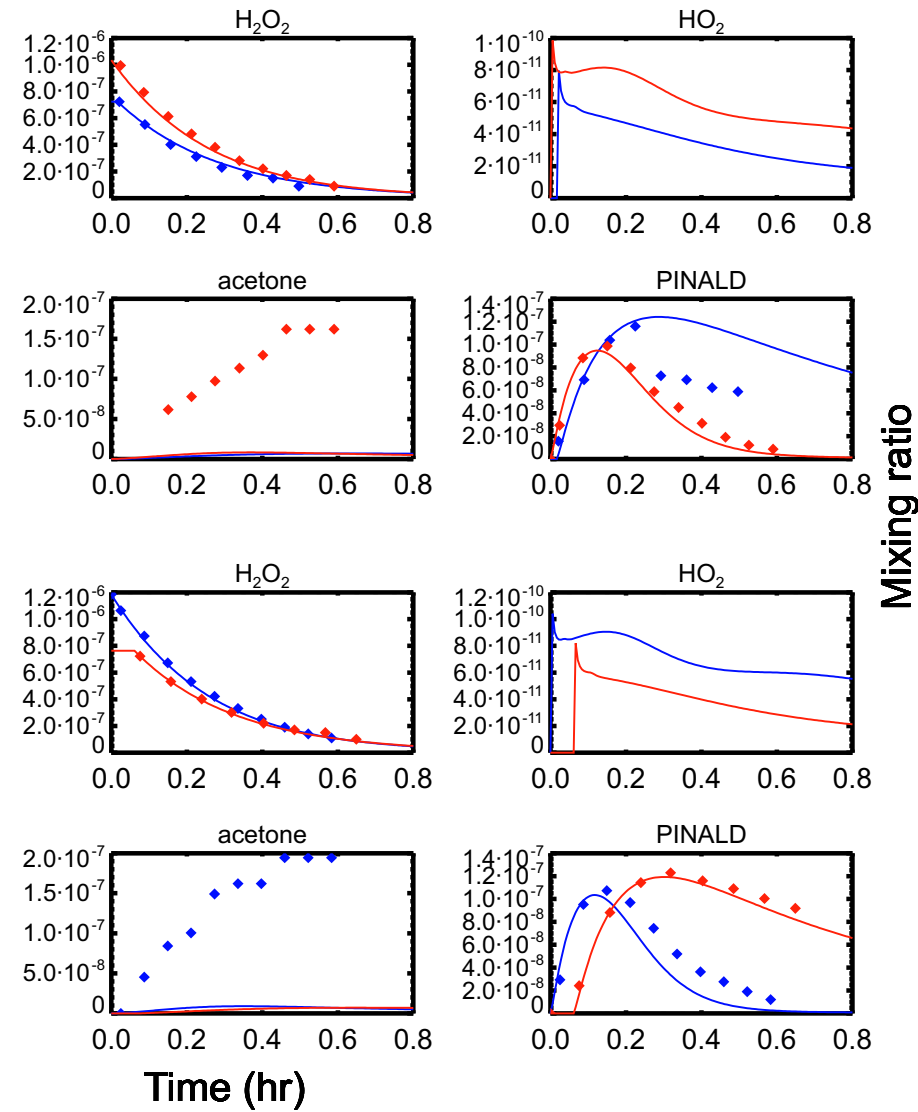

Fig. 7. Measured (diamonds) vs simulated (curves) concentrations as a function of time for several experiments of $\alpha$-pinene oxidation in UV conditions in the absence of $\mathrm{NO}_{\mathrm{X}}$ : (a) Experiments 24 and 29, (b) Experiments 30 and 25 from N99.

of $\mathrm{X}$ and the reactant, ( $\alpha$-pinene or pinonaldehyde) at time $t$. $[\operatorname{REACTANT}(0)]$ is the initial concentration of the reactant. However, it is easy to see that even small errors on the concentrations can lead to large errors on the yields. Also, any delay between the time when $[\operatorname{REACTANT}(0)]$ is measured and the actual start of the experiment can have large effects. For larger $t$ values, the relative errors on $[\mathrm{X}(t)]$ and on the difference [REACTANT(0)]-[REACTANT $(t)]$ become less important, but the photochemical sink and the secondary production play a larger role, which is difficult to quantify. Therefore, instead of comparing "true" yields, it is more meaningful for the purpose of mechanism validation to compare the observed concentrations $[\mathrm{X}(t)]$ with concentrations calculated using a "box" model.

In order to quantify the model/data biases in a systematic way, we average the apparent yields deduced at measurement times $t_{i}$ comprised between $10 \%$ to $60 \%$ of $\alpha$-pinene conversion, i.e. a time interval of typically about $10 \mathrm{~min}$. Data before $10 \%$ of $\alpha$-pinene conversion are discarded in order to minimize the relative errors on $[\triangle \operatorname{APIN}(t)]$ and on the product concentrations, whereas data after $60 \%$ of $\alpha$-pinene conversion are rejected to moderate the influence of product losses and secondary productions. These processes are taken into account in the model, but to a much lesser degree of detail than the pathways leading to the primary products. For example, the experimental average apparent yield of a product $\mathrm{X}$ is calculated as:

$\bar{Y}_{\mathrm{app}}^{\mathrm{obs}}(\mathrm{X})=\frac{\sum_{i=1}^{n} Y_{\mathrm{app}}^{\mathrm{obs}}\left(\mathrm{X}, t_{i}\right)}{n}$,

where $n$ is the number of samplings between $10 \%$ and $60 \%$ $\alpha$-pinene converted. The corresponding model apparent yield $\left(\bar{Y}_{\text {app }}^{\bmod }(\mathrm{X})\right)$ is deduced in a similar way using the modelled values of $\mathrm{X}$ at the same measurement times $t_{i}$. Note that the apparent yields deduced from both the model and the observation are calculated using the $\alpha$-pinene concentrations from the model.

The comparison between experimental and simulated apparent yields is meaningful only if the model is able to reproduce properly the observed variation of $\alpha$-pinene. This is indeed the case for most experiments. The mean bias between the modelled and measured $\alpha$-pinene concentrations 

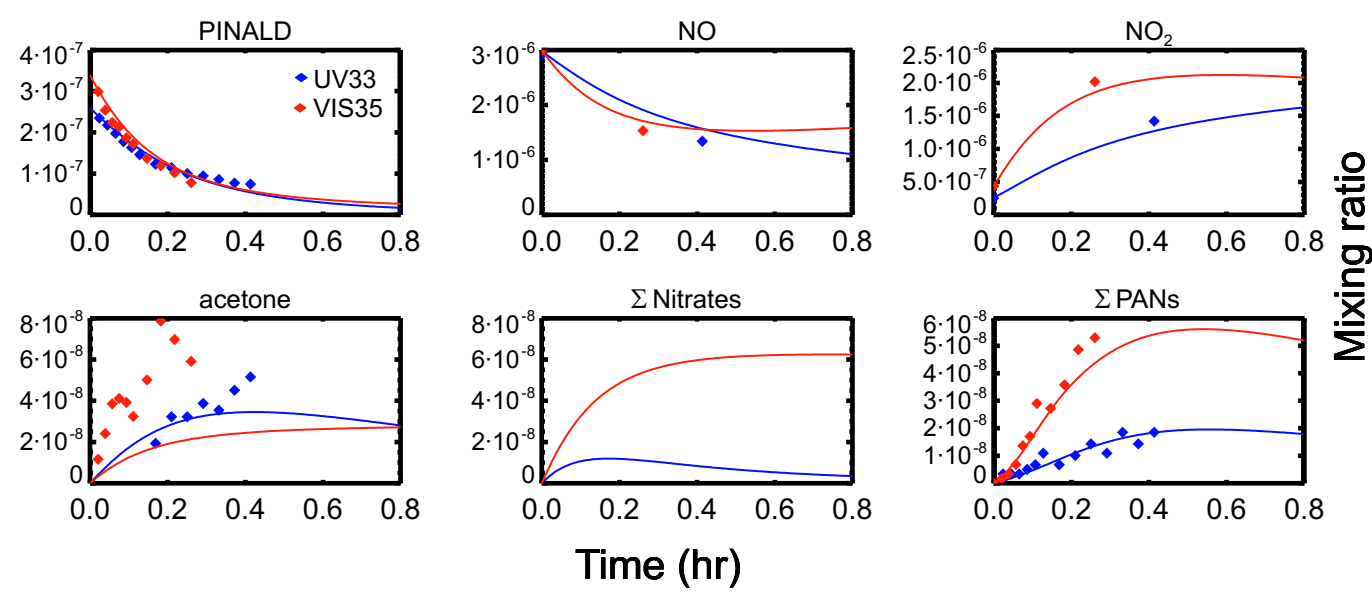

Fig. 8. Measured (diamonds) vs simulated (curves) concentrations as a function of time for an experiment of pinonaldehyde oxidation in UV (experiment 33, blue lines), and in visible conditions (experiment 35, red lines) in the presence of $\mathrm{NO}_{\mathrm{x}}$ from $\mathrm{N} 99$.

is below $10 \%$ for more than $70 \%$ of the experiments. Experiments showing a mean bias higher than $10 \%$ are discarded from our analysis. On average, the valid experiments show a mean bias that does not exceed 5\%.

Secondary productions of a compound $\mathrm{X}\left(Y_{\mathrm{sec}}\right)$ may result from the photooxidation of other primary products, e.g. pinonaldehyde. The losses $(L)$ of $\mathrm{X}$ occur via oxidation by $\mathrm{OH}$, photolysis and, of least importance, by loss on the walls. $\bar{L}(\mathrm{X})$ and $\bar{Y}_{\mathrm{sec}}(\mathrm{X})$ are averaged over the $n$ sampling times of $\mathrm{X}$ in the same fashion as in Eq. (8). The values of $Y(\mathrm{X})$ reported in this study are the theoretical yields obtained following Eq. (6). In principle, the yield of X can vary in the course of an experiment, because it is a function of the conditions ([NO], $\left.\left[\mathrm{NO}_{2}\right],\left[\mathrm{HO}_{2}\right] \ldots\right)$ which influence the fate of peroxy radicals. In practice, however, these conditions do not vary dramatically in the $\mathrm{N} 99$ experiments and $Y(\mathrm{X})$ is almost constant during an experiment. Therefore, if the samplings of $\mathrm{X}$ are made in the early experimental times, we obtain the following relation:

$Y(\mathrm{X}) \approx \bar{Y}_{\mathrm{app}}(\mathrm{X})+\bar{L}(\mathrm{X})-\bar{Y}_{\mathrm{sec}}(\mathrm{X})$.

The yields $Y$, as well as the average apparent yields, $\bar{Y}_{\text {app }}(\mathrm{X})$, the losses $\bar{L}(\mathrm{X})$ and secondary productions $\bar{Y}_{\mathrm{sec}}(\mathrm{X})$ are summarized in Table 8. They are all expressed as molar yields, i.e. as percentages of $\alpha$-pinene converted. The yields reported by N99 are also shown. The variability in the modelled values are due to $1 /$ differences in the initial conditions of NO and $2 /$ differences in the sampling times. The time concentrations calculated by the model are compared with the measured concentrations in Fig. 5 (visible, in presence of NO), Fig. 6 (UV, in presence of NO) and Fig. 7 (UV, NOfree).

The same methodology was used for the pinonaldehyde experiments. However, the strong photolysis of pinonaldehyde in the UV experiments contributes to the product concentrations. Therefore $Y(\mathrm{X})$ has to be corrected by retrieving the production from the photolysis and readjusting the yield to the actual $[\Delta$ (PINALD)] that has reacted with $\mathrm{OH}$. In the visible conditions, the photolysis of pinonaldehyde is weak, and no correction is needed.

Only two pinonaldehyde $+\mathrm{OH}$ experiments were performed in UV conditions. The model fails to reproduce the degradation of pinonaldehyde ( $>10 \%$ deviation) for one of them. In the visible, the pinonaldehyde decay rate is well caught by the model for the three experiments reported. On average, the mean bias between the modelled and measured pinonaldehyde concentrations is about $5 \%$. Results are reported in Table 8 and shown in Fig. 8.

\section{$3.3 \alpha$-pinene comparison results}

\subsection{1 $\alpha$-pinene and $\mathrm{OH}$-precursors}

As explained previously, the intensity of the lamps in the model are adjusted on the measured decay rates of the $\mathrm{OH}-$ precursors. These rates are found to be essentially constant, demonstrating the stability of the lamps. The degradation of $\alpha$-pinene is well simulated in the UV conditions in presence as well as in absence of NO, indicating that the processes determining the concentration of $\mathrm{OH}$ are generally well represented by the model. In the visible conditions, the large production of formaldehyde generated through the degradation of $\mathrm{CH}_{3} \mathrm{ONO}$ (Eq. R22) as well as the concentration of $\mathrm{NO}$ are well reproduced. This indicates that the photolysis of $\mathrm{CH}_{3} \mathrm{ONO}$ is correctly estimated and so is the primary production of $\mathrm{OH}$ (through Eq. R24) in the reactor for these conditions. However, discrepancies appear at longer experimental times between the modelled and measured $\alpha$-pinene degradation rates for about half the experiments simulated in the visible conditions. Examples of this behaviour are seen in experiments 4 and 5 in Fig. 5. The bias is small $(<10 \%)$ in the first stage of the experiment (before $60 \%$ of $\alpha$-pinene 
conversion) and it does not influence the estimation of the primary product yields. The discrepancy at later times seems to be independent on the initial concentrations or on the evolution of the photochemical conditions in the course of the experiment (e.g. abrupt decrease of the NO level).

\subsubsection{Pinonaldehyde}

The pinonaldehyde concentrations are very well reproduced by the model in presence (Figs. 5 and 6) as well as in absence (Fig. 7) of NO, in particular in the first stage of the experiments $(<60 \% \alpha$-pinene conversion). This is reflected by the excellent agreement obtained regarding the apparent yields of pinonaldehyde, as defined by Eq. (8) (see Table 8). In presence of NO, the yield of pinonaldehyde (i.e. the yield corrected for its different losses) is calculated to be $55.5 \%$ for an initial concentration of NO of $3 \mathrm{ppm}$. The strong photolysis of pinonaldehyde in the UV conditions explains the lower apparent yields in the UV compared to the visible conditions, where photolysis plays a negligible role (Table 8). In both series of experiments, the reaction of pinonaldehyde with $\mathrm{OH}$ represents $8-9 \%$ of the reacted $\alpha$-pinene. As much as $10-25 \%$ of the pinonaldehyde produced when $60 \%$ of $\alpha$ pinene has reacted is photooxidized in this interval. In the later stages of the experiments, when the oxidation of the primary products plays a more important role in the reactor, pinonaldehyde is overestimated by the model in about half the visible experiments. The reason for this discrepancy might be the oversimplified treatment of the oxidation mechanism of the primary products.

In absence of $\mathrm{NO}_{\mathrm{x}}$, pinonaldehyde is produced exclusively from cross reactions of peroxy radicals. About $10 \%$ among the $26 \%$ pinonaldehyde yield come from reactions of $\mathrm{R}_{12} \mathrm{O}_{2}$ (see Fig. 1). The self-reaction rate of this tertiary radical explains that it reacts for about $50 \%$ with $\mathrm{HO}_{2}$, thereby contributing to about $8 \%$ among the total $30 \%$ of peroxides generated in the system. The remaining $50 \%$ of the $\mathrm{R}_{12} \mathrm{O}_{2}$ radicals react mainly with acyl peroxy radicals, then with $\mathrm{O}_{2}$, producing $\mathrm{R}_{13} \mathrm{O}_{2}$. The fast decomposition of $\mathrm{R}_{13} \mathrm{O}_{2}$ outruns its reaction with $\mathrm{HO}_{2}$ and other $\mathrm{RO}_{2} \mathrm{~s}$, producing pinonaldehyde. The other channel leading to pinonaldehyde (16\%) proceeds via the secondary radical $\mathrm{R}_{2} \mathrm{O}_{2}$. The high selfreaction rate allows $\mathrm{R}_{2} \mathrm{O}_{2}$ to react for $90 \%$ via the permutation reactions. Among them, the reaction of $\mathrm{R}_{2} \mathrm{O}_{2}$ with the $\beta$-hydroxy secondary radicals (actually mainly composed of $\left.\mathrm{R}_{2} \mathrm{O}_{2}\right)$ is the preferred pathway $(\sim 40 \%)$. The other permutation reactions contribute equally $(\sim 5-10 \%)$ at the exception of the cross reactions with the alkyl tertiary radicals R3R which are negligible.

N99 reported yield estimates about 10\% higher than reported here. Considering the difficulty to retrieve true product yields from the measured concentrations and the large uncertainties in the reaction rates of large peroxy/alkoxy organic radicals in the mechanism, these estimates are in fairly good agreement with our model.

\subsubsection{Acetone}

The calculated primary yield of acetone for a mean initial concentration of NO of $3 \mathrm{ppm}$ is $11 \%$, in good agreement with N99. The sink of acetone is small: oxidation by $\mathrm{OH}$ is negligible, and photolysis plays at most a minor role. The secondary production of acetone originates from the photooxidation of pinonaldehyde. It is more important in the experiments using the UV lamp due to the higher photodissociation rate of pinonaldehyde under these conditions. Considering the large dispersion in the data, the model reproduces quite well the time evolution of acetone.

An important disagreement exists for acetone in the experiments without $\mathrm{NO}_{\mathrm{x}}$. The data show a significant production of acetone $(\approx 10 \%$ yield $)$ through primary or/and secondary reactions in these conditions, whereas the model simulates a production close to zero. As explained in Sect. 2.3, the ring closure reaction of $\mathrm{R}_{7} \mathrm{O}_{2}$ outruns the channel leading to the production of acetone in presence of NO. Due to the lack of measurements in the early stages of the experiments, the acetone yields (Table 8) are calculated using concentration data for $\alpha$-pinene conversions from 60 to $90 \%$. The observed production of acetone in $\mathrm{NO}_{\mathrm{x}}$-free conditions might have primary as well as secondary origins. In a sensitivity test, turning off the ring closure reactions in the model (thus freeing the path to $\mathrm{R}_{7}$ ) results in only $3.5 \%$ acetone. This low production is due to the tertiary structure of the peroxy radical $\mathrm{R}_{7} \mathrm{O}_{2}$ which favours the reaction with $\mathrm{HO}_{2}$ against the permutation reactions. In the event that ring closure is dominant, we estimate the highest possible (primary) acetone yield to $6 \%$, which is the value obtained by hypothesizing that acetone is produced immediately upon decomposition of $\mathrm{R}_{8} \mathrm{O}$ (generated from reactions of $\mathrm{R}_{8}$ with $\mathrm{O}_{2}$ and then with other peroxy radicals). Secondary productions are therefore required in order to account for the high observed yield. This is also suggested by the concentration-time profiles in Fig.7 since acetone is seen to increase even after complete oxidation of $\alpha$-pinene.

\subsubsection{Formaldehyde}

The model cannot reproduce the large formaldehyde concentrations measured in the UV experiments. However, the measured production of formaldehyde appears to be constant in time (experiments 3 and 17 in Fig. 6) and independent on the photochemical regime (experiments 25 and 30 in Fig. 7), suggesting a desorption of this compound from the walls. This effect is not seen in the visible conditions because of the large amount of formaldehyde generated by the photolysis of CH3ONO (experiment 4 in Fig. 5). The modelled primary yield is $12.6 \%$ at high $\mathrm{NO}_{\mathrm{x}}$ concentrations. The main production pathways proceed through the reactions of the radicals $\mathrm{R}_{3} \mathrm{O}_{2}$ and $\mathrm{R}_{13} \mathrm{O}_{2}$ with NO. Secondary productions originate from the photooxidation of pinonaldehyde $(6 \%)$ and from other sources $(3 \%)$. Yield values are not reported for 

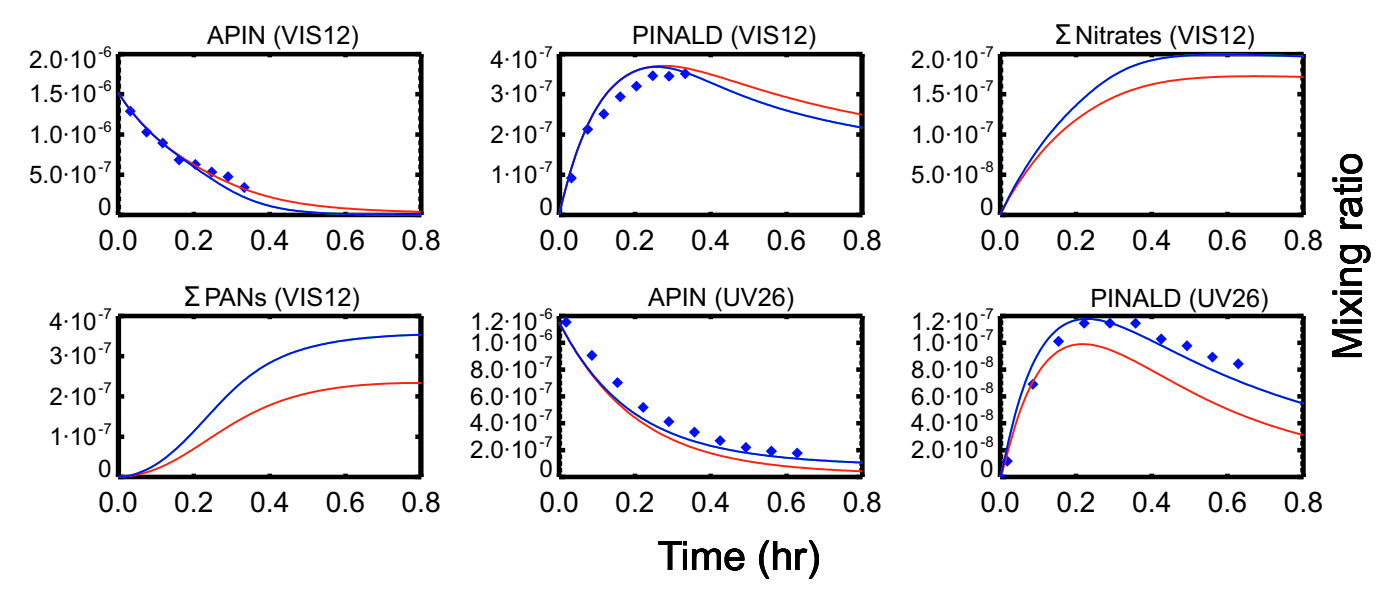

Fig. 9. Modelled concentrations when the chemistry of the generic radicals LXO2 and SXO2 (see Sect. 2.4) is omitted (red lines), and comparison with the standard case (blue lines). Effects in presence and absence of $\mathrm{NO}_{\mathrm{x}}$ are represented by experiments VIS12 and UV26, respectively.

the visible experiments, since methyl nitrite photolysis generates large quantities of formaldehyde. The formaldehyde yield is very low in the $\mathrm{NO}_{\mathrm{x}}$-free experiments. This is due to the fast decomposition of the radicals $\mathrm{R}_{3} \mathrm{O}_{2}$ and $\mathrm{R}_{13} \mathrm{O}_{2}$ to pinonaldehyde, outrunning the formation of formaldehyde through these radicals. The other channel (via $\mathrm{R}_{6}$ and $\mathrm{R}_{7} \mathrm{O}_{2}$ ) leads to $\mathrm{R}_{8}$ for which we have no explicit mechanism. Therefore we can assume that, as for acetone, formaldehyde is underestimated in the model in absence of NO.

\subsubsection{Nitrates}

The total concentration of organic nitrates (mainly made of $\mathrm{C}_{\geq 7}$ compounds) generated by the $\alpha$-pinene oxidation were quantified by $\mathrm{N} 99$ on the basis of the integrated cross sections $\left(\sigma_{\text {int }}\right)$ of 2-hydroxypinane-3-nitrate and 3-oxopinane-2nitrate in the range $1635-1700 \mathrm{~cm}^{-1}$. The first compound represents $20 \%$ of the total amount of nitrates produced according to the mechanism, whereas the latter is not produced. However, the great majority of the nitrates generated in the $\alpha$-pinene mechanism have a structure comparable to 2 hydroxypinane-3-nitrate (presence of a cycle, presence of an alcohol function, and similar number of carbons), so that we can consider plausible that they absorb in a similar fashion as 2-hydroxypinane-3-nitrate and 3-oxopinane-2-nitrate.

The model reproduces quite well the observed apparent yields for both actinic conditions. The nitrates were quantified in only one experiment in the UV series. In that case, the data at longer times show a sharp increase of the nitrates concentration that could not be reproduced by the model.

The experiments in the visible were performed at different pressures of $\mathrm{O}_{2}$ : Experiments 5 and 10 at $P_{\mathrm{O}_{2}}=10 \mathrm{mbar}$, experiment 4 at $P_{\mathrm{O}_{2}}=26 \mathrm{mbar}$ and experiment 12 at $P_{\mathrm{O}_{2}}=200$ mbar. Varying the pressure of $\mathrm{O}_{2}$ affects the decay rate of $\mathrm{CH}_{3} \mathrm{ONO}$. This is due to the main reactions involving
$\mathrm{CH}_{3} \mathrm{O}$, which is produced by Reaction (R22):

$$
\begin{aligned}
& \mathrm{CH}_{3} \mathrm{O}+\mathrm{O}_{2} \rightarrow \mathrm{CH}_{2} \mathrm{O}+\mathrm{HO}_{2} \\
& \mathrm{CH}_{3} \mathrm{O}+\mathrm{NO}+\mathrm{M} \rightarrow \mathrm{CH}_{3} \mathrm{ONO} \\
& \mathrm{CH}_{3} \mathrm{O}+\mathrm{NO}_{2}+\mathrm{M} \rightarrow \mathrm{CH}_{3} \mathrm{ONO}_{2} .
\end{aligned}
$$

Reactions (R28) and (R29) are negligible at standard pressure but they compete with Reaction (R27) at low oxygen pressure, resulting in $\mathrm{CH}_{3} \mathrm{ONO}$ reformation and in a large production of methyl nitrate. Experiment 4,5 and 10 produce 15,20 and $50 \%$ of $\mathrm{CH}_{3} \mathrm{ONO}_{2}$, respectively, whereas the yield of $\mathrm{CH}_{3} \mathrm{ONO}_{2}$ is only $3 \%$ in experiment 12 . In Figs. 5, 6,8 , and in Table 8 , " $\Sigma$ Nitrates" represents the total nitrates excluding $\mathrm{CH}_{3} \mathrm{ONO}_{2}$.

N99 as well as Hatakeyama et al. (1991) reported molar aerosol yields on the order of $20 \%$ for $\sim 1 \mathrm{ppm}$ of $\alpha$-pinene, whereas a maximum yield of 5\% for $500 \mathrm{ppt} \alpha$-pinene are deduced from the experiments performed by Bonn and Moortgat (2002). The contribution of hydroxy nitrates to these measured yields is likely to be substantial. According to the theory developed by Bowman et al. (1997), the gas/particle partitioning ratios is related to the vapour pressure of the compound considered. The vapour pressures of small alcohols and diols are usually similar to the vapour pressures of nitrates and dinitrates of corresponding structure (Lide, 2001). On the basis of the relationships defined by Makar (2001) between the vapour pressure and the carbon number for alcohols and nitrates, we can expect the hydroxy nitrates species of higher carbon number produced in the oxidation of $\alpha$-pinene by $\mathrm{OH}$ to have a vapour pressure of the order of $10^{-5}$ torr (to be compared with the vapour pressure of pinonaldehyde: $3.8 \times 10^{-2}$ torr (Hallquist et al., 1997)). N99 suggested that both gas-phase and condensed organic nitrates contribute to the absorption band, therefore the influence of the partitioning is not visible in the measurements. 


\subsubsection{PANs}

Measurements of peroxy acetyl nitrate (PAN) and $\alpha$-pinonyl peroxy nitrate ( $\alpha$-PPAN) were carried out for almost all UV experiments. $\alpha$-PPAN is the main PAN analogue produced in the pinonaldehyde oxidation by $\mathrm{OH}$ (Fantechi et al., 2002). These measurements should be considered with caution, since many other PAN analogues are produced in the mechanism, which can be expected to have very similar IR spectra (Nozière and Barnes, 1998). For example, PAN analogues (e.g. benzoylperoxy nitrate and peroxy methacryloyl nitrate) show a peak within $1 \mathrm{~cm}^{-1}$ of PAN in the main band of their spectra (at $1741 \mathrm{~cm}^{-1}$ ). It follows that the spectroscopic measurements of PAN and $\alpha$-PPAN in N99 experiments cover all PAN analogues similar to PAN and $\alpha$ PPAN in the reactor. Therefore, we make the assumption that the sum of the measured concentrations of PAN and $\alpha$ PPAN should be close to the sum of all PANs in the system ( $\sum$ PANs). Figures 5 and 6 display also the sum of PAN and $\alpha$-PPAN (lower curve) as calculated by the model for illustration purposes (the upper curve representing $\Sigma$ PANs). In general, the model agrees well with the measurements in both $\mathrm{UV}$ and visible conditions.

In absence of vapour pressures data for PANs, the vapour pressures of (hydroxy-)PANs can be assumed to be similar to the vapour pressures of (hydroxy-)nitrates. Therefore, we can expect hydroxy-PANs (representing about $30 \%$ of the total PANs) to partition also to the aerosol phase. The partitioning of these semi-volatile compounds is expected to have a influence on the yields of the gas-phase PANs.

\subsection{Pinonaldehyde+OH comparison results}

It is more difficult to draw precise conclusions regarding the pinonaldehyde $+\mathrm{OH}$ experiments, due to the small number of experiments. The experiment in the UV indicates an acetone apparent yield around 20\% (Table 8 and Fig. 8) which is well reproduced by the model. In the UV conditions, $30 \%$ of the pinonaldehyde present in the reactor photolyse while $8 \%$ are lost by adsorption on the walls, leaving only $62 \%$ reacting with $\mathrm{OH}$. This explains the large amount of acetone produced in the experiment, whereas the primary yield from pinonaldehyde $+\mathrm{OH}$ only is actually twice lower. Photolysis of pinonaldehyde is assumed to occur mainly around the ketone function in the UV. The bond breaking promotes the $\mathrm{R}_{4}$ radical (see Fig. 2) leading to acetone. The model calculates that photolysis yields as much as $50 \%$ of acetone in these conditions. The apparent yield as well as the primary yield of acetone are in good agreement with the estimations of N99 for the UV conditions. The modelled apparent yield of acetone is lower in the experiments conducted under visible light because photolysis is negligible in these conditions. However the data show the opposite with a twice higher yield in the visible experiments. The causes of these differences are unclear.

\subsection{Sensitivity studies}

We evaluate the sensitivity of the model results to three sources of uncertainties. The first and probably most important of all is the incompleteness of the mechanism. As discussed in Sect. 2.4, the reactions of many primary products and radicals are treated in a crude way in the model. In order to assess the impact of these reactions, the standard model results are compared with simulations where the reactions of the generic peroxy radicals LXO2 and SXO2 (Eqs. R13a to R18) are switched off. Figure 9 shows typical simulation results in presence and in absence of NO. When NO is present, the influence of the generic peroxy radicals on the concentrations (and therefore on the primary products yields) is negligible in the first stage of the experiment, because the conversion of $\mathrm{NO}$ to $\mathrm{NO}_{2}$ are due to radicals generated in the first reactions in the oxidation of $\alpha$-pinene. Later on, the chemistry of the primary products becomes more important. When $\alpha$-pinene is almost entirely oxidized, the $\mathrm{NO}$ to $\mathrm{NO}_{2}$ conversion is largely supported by the chemistry of LXO2 and SXO2. This is noticeable on the total PANs concentrations, which are lowered by about $35 \%$ when this chemistry is omitted.

In absence of NO, the pinonaldehyde yield is significantly reduced (to $17 \%$ ) when the chemistry of the generic radicals is switched off. This is due to the fact that the ring closure of $\mathrm{R}_{7} \mathrm{O}_{2}$ promoted by the absence of $\mathrm{NO}$ produces large amounts of $\mathrm{LXO} 2$ in the first steps of the oxidation process. These radicals contribute largely to the cross reactions producing pinonaldehyde.

Although the use of generic radicals allows to simulate $\mathrm{NO}$ to $\mathrm{NO}_{2}$ conversions and permutation reactions missing in our mechanism, it should be considered with caution, especially in $\mathrm{NO}_{\mathrm{x}}$-free conditions. The values of $\lambda$ and the $\alpha_{i}$ in Eqs. (R12), (R15) and (R19) are indeed based on the high-NO assumption. However, this method appears to be valid for the simulations presented in this study. For example, the simulated concentrations of total PANs as well as pinonaldehyde in absence of NO (both largely dependent on the chemistry of the generic radicals) reproduce well the measurements. The other products are not much influenced by this chemistry: e.g. the total peroxide yield in $\mathrm{NO}_{\mathrm{x}}$-free conditions goes down by only 5\% (from the standard case of $30 \%$ ) and the total organic nitrate yield decreases only from $14 \%$ to $12 \%$ in the experiments in presence of $\mathrm{NO}_{\mathrm{x}}$.

Performing the same sensitivity test in the simulations of typical atmospheric conditions (see Sect. 3.6), it is found that the chemistry of the generic radicals has little influence on the primary yields of pinonaldehyde and acetone. Our representation of the missing chemistry in the mechanism can therefore be considered as reasonably accurate for predicting the product concentrations in the first stages of the oxidation of $\alpha$-pinene.

In another sensitivity test, the uncertainties related to the rates of the reactions of inorganic and small $\left(\mathrm{C}_{\leq 3}\right)$ com- 

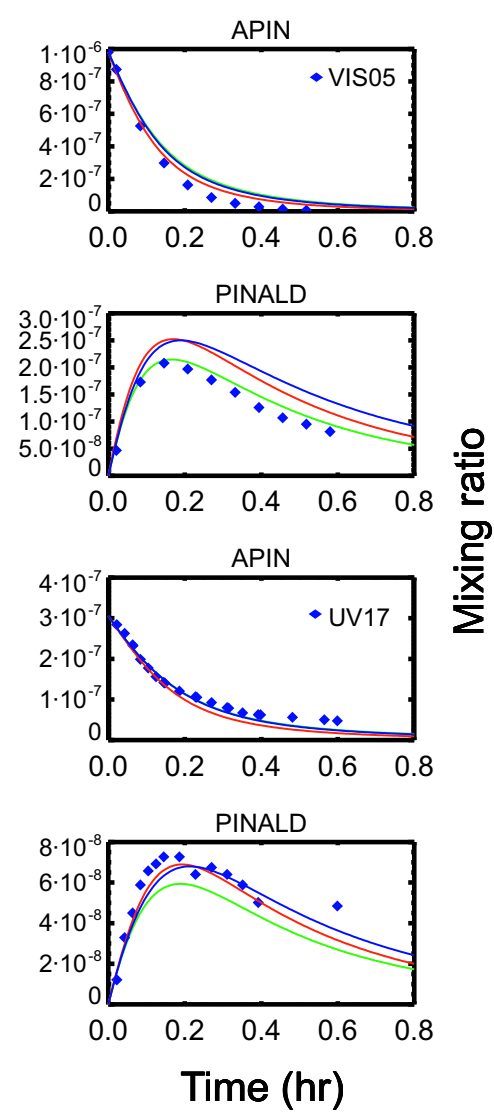

Fig. 10. Modelled concentrations when the rates from DeMore et al. (1997) and Sander et al. (2000) are used (red lines) instead of the corresponding rates from Atkinson et al. (2003) (standard case, blue lines). The results using $k($ pinald $+\mathrm{OH})=5 \times 10^{-11} \mathrm{~cm}^{-3}$ molec $^{-1} \mathrm{~s}^{-1}$ are also shown (green lines).

pounds have been investigated. For that purpose, the rates proposed by Atkinson et al. (2003) (IUPAC) for these reactions are replaced by those proposed by DeMore et al. (1997) and Sander et al. (2000) (JPL). This substitution affects the levels of $\mathrm{OH}$ and, therefore, the oxidation rate of $\alpha$-pinene. As seen in Fig. 10, this rate is slightly higher when the JPL set is used. This difference is mainly due to two reactions:

$\mathrm{OH}+\mathrm{OH}+\mathrm{M} \rightarrow \mathrm{H}_{2} \mathrm{O}_{2}+\mathrm{M}$

and,

$\mathrm{OH}+\mathrm{NO}+\mathrm{M} \rightarrow \mathrm{HONO}+\mathrm{M}$.

Atkinson et al. (2003) report rates of $5.26 \times 10^{-12}$ and $9.71 \times 10^{-12} \mathrm{~cm}^{3} \mathrm{molec}^{-1} \mathrm{~s}^{-1}$ for Reactions R30 and R31, respectively, whereas DeMore et al. (1997) gives different rates for both reactions, $5.98 \times 10^{-12}$ and $7.39 \times 10^{-12} \mathrm{~cm}^{3} \mathrm{molec}^{-1} \mathrm{~s}^{-1}$, respectively. When the JPL set is used in the visible simulations, the modelled apparent yield of pinonaldehyde is overestimated by $5 \%$, a larger discrepancy than when the IUPAC set is used (2\%). These changes remain reasonably small.

The rate of $3.5 \times 10^{-11} \mathrm{~cm}^{3}$ molec $^{-1} \mathrm{~s}^{-1}$ proposed by Fantechi et al. (2002) is used in the model for the reaction of pinonaldehyde with $\mathrm{OH}$. This value based on theoretical calculations is in fair agreement with the two most recent experimental values of $4-5 \times 10^{-11} \mathrm{~cm}^{3} \mathrm{molec}^{-1} \mathrm{~s}^{-1}$ (Alvarado et al., 1998; Nozière et al., 1999b). Setting the rate to the higher limit of $5 \times 10^{-11} \mathrm{~cm}^{3} \mathrm{molec}^{-1} \mathrm{~s}^{-1}$ in the model leads to a slightly better match with the data for pinonaldehyde in visible conditions (Fig. 10). However in the UV conditions, pinonaldehyde is underestimated, with a calculated apparent yield of $41 \%$.

3.6 Influence of the photochemical conditions on the modelled product yields

The yield of pinonaldehyde is controlled by reactions of peroxy radicals: the reactions with $\mathrm{NO}$, with $\mathrm{HO}_{2}$ and with the other peroxy radicals in the case of the radicals $\mathrm{R}_{2} \mathrm{O}_{2}$ and $\mathrm{R}_{12} \mathrm{O}_{2}$; and the reaction with $\mathrm{NO}$ and the decomposition reaction in the case of the $\alpha$-hydroxyalkyl peroxy radicals: $\mathrm{R}_{3} \mathrm{O}_{2}, \mathrm{R}_{3} \mathrm{O}_{2}^{\dagger}, \mathrm{R}_{13} \mathrm{O}_{2}, \mathrm{R}_{13} \mathrm{O}_{2}^{\dagger}$ (Fig. 1). Consequently, as explained in Sect. 2.3, the yield depends on the photochemical conditions. Figure 11 represents the yield of pinonaldehyde as a function of $\mathrm{NO}$ and $\alpha$-pinene. The solid blue line is the yield generated by the model with an initial concentration of $\alpha$-pinene of $400 \mathrm{ppb}\left(1 \times 10^{13} \mathrm{~cm}^{3}\right.$ molecule $\left.{ }^{-1}\right)$, typical of the $\mathrm{N} 99$ experiments (standard case). In the chemical regime (A) (a "low $\mathrm{NO}_{\mathrm{x}}$ " regime), the cross reactions of the peroxy radicals are dominant over the reactions with $\mathrm{NO}$ and the decomposition Reaction (R8a) and (R9) are the only reactions of the $\alpha$-hydroxyalkyl peroxy radicals. The pinonaldehyde yield is limited by the alkoxy channel ratio in the permutation reactions of $\mathrm{R}_{2} \mathrm{O}_{2}$ and $\mathrm{R}_{12} \mathrm{O}_{2}$. The regime (B) is characterized by a transition where the NO-reaction of $\mathrm{R}_{2} \mathrm{O}_{2}$ and $\mathrm{R}_{12} \mathrm{O}_{2}$ compete with the permutation reactions. This transition takes place at higher NO levels when the concentration of $\alpha$-pinene is augmented, as shown by the dotted blue line in Fig. 11 calculated using a higher $\alpha$-pinene level. The highest yield $(61 \%)$ is reached when the NO-reaction is the only reaction for the radicals $\mathrm{R}_{2} \mathrm{O}_{2}$ and $\mathrm{R}_{12} \mathrm{O}_{2}$, and is still negligible compared to decomposition of the $\alpha$-hydroxyalkyl peroxy radicals (R9) (regime C). For NO $>100 \mathrm{ppb}$ (regime D) $\mathrm{k}_{R 10}$ becomes effective and reduces the production of pinonaldehyde. However the reaction of the tertiary radical $\mathrm{R}_{3} \mathrm{O}_{2}$ with NO plays only a minor role for NO concentrations below $10 \mathrm{ppm}$.

Other $\alpha$-pinene+OH experiments were performed with NO levels similar to those used in N99: Hatakeyama et al. (1991) derived a yield of $78.5 \%$ (value adjusted by N99), whereas Wisthaler et al. (2001) deduced a yield of $34 \pm 9 \%$. A few experiments were made at higher concentrations of NO. Arey et al. (1990) and Hakola et al. (1994), with about $10 \mathrm{ppm}$ of NO derived yields of $28 \pm 5 \%$ and $29 \pm 5 \%$ respec- 


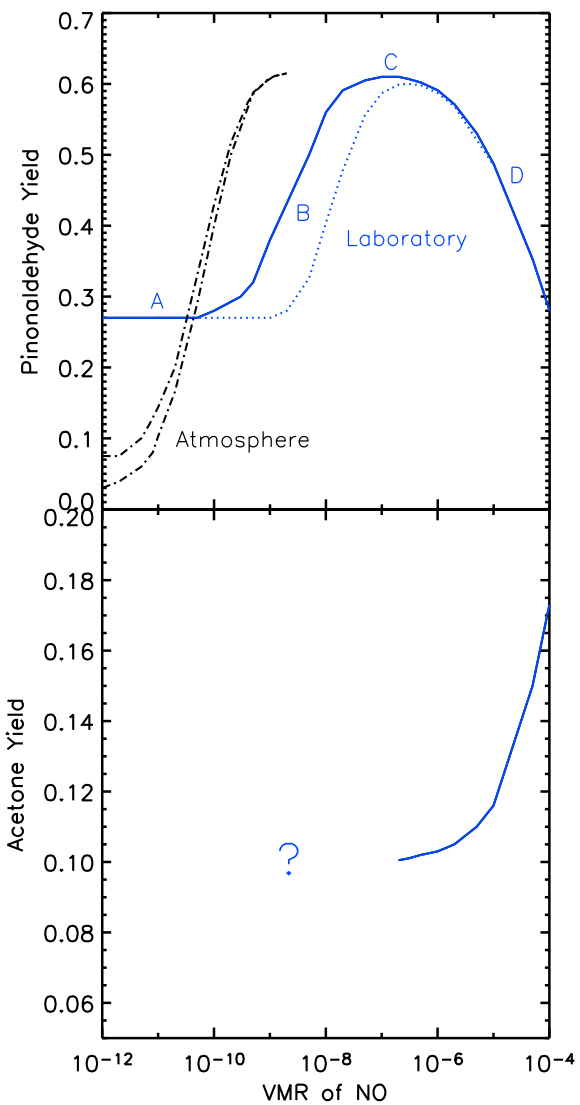

Fig. 11. Yields of pinonaldehyde (upper panel) and acetone (lower panel) as a function of the NO volume mixing ratio (VMR). The blue curves correspond to laboratory conditions, with $[\alpha$ pinene $]=400 \mathrm{ppb}$ (solid lines) or $[\alpha$-pinene $]=20 \mathrm{ppm}$ (dotted lines). The black curves correspond to atmospheric conditions, with $[\alpha-$ pinene $]=100 \mathrm{pptv}$ or $[\alpha$-pinene $]=500 \mathrm{pptv}$ (dash dotted lines).

tively. These results are in fair agreement with the modelled yield considering the uncertainty on the rates $\mathrm{k}_{R 8 \mathrm{a}}, \mathrm{k}_{R 8 \mathrm{~b}}$ and $\mathrm{k}_{R} 9$. They tend to confirm the predicted decrease of the pinonaldehyde yield for NO concentrations higher than $100 \mathrm{ppb}$.

The yield of acetone is also dependent of NO. For $\mathrm{NO}<1 \mathrm{ppb}$, the ring closure reaction of radicals $\mathrm{R}_{7} \mathrm{O}_{2}$ outruns the other reactions and the acetone production pathway proceeding through the reaction of $\mathrm{R}_{7} \mathrm{O}_{2}$ with $\mathrm{NO}$ or $\mathrm{RO}_{2}$ is negligible. The ring closure products being not explicitly known, it is unfortunately not possible to provide theoretical estimates of the acetone yield at low $\mathrm{NO}_{\mathrm{x}}$ (regime $\mathrm{A}$ and $\mathrm{B})$. In regime $(\mathrm{C})(\mathrm{NO} \geq 100 \mathrm{ppb})$, the ring closure reaction becomes negligible and the acetone yield is estimated to be about $10 \%$. In regime (D), the channel promoted by $\mathrm{R}_{3} \mathrm{O}_{2}+\mathrm{NO}$ brings an additional contribution to the primary yield of acetone which reaches $17 \%$ for $100 \mathrm{ppm}$ of NO.

In the atmosphere, the abundances of $\alpha$-pinene and NO are usually much lower than in the reactor. Typical atmospheric

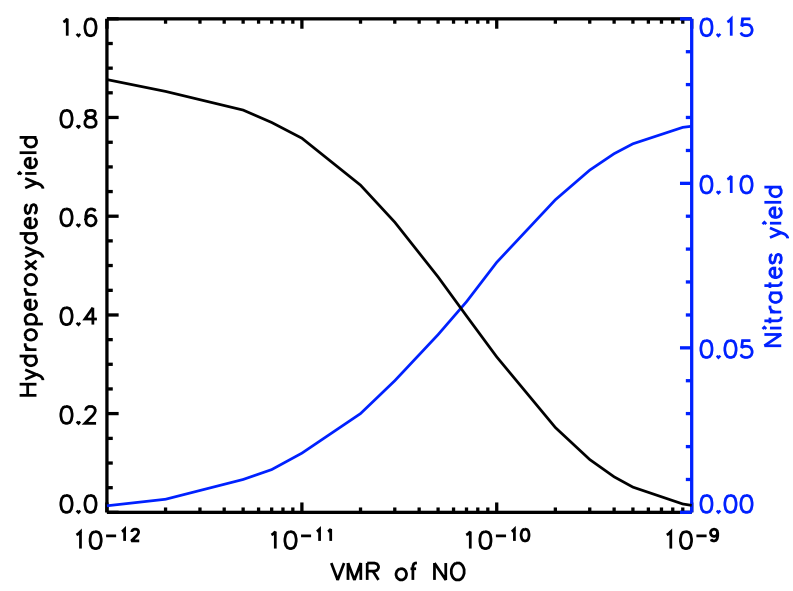

Fig. 12. Primary yields of total hydroperoxide (black curve) and total nitrate (blue curve) as a function of the NO volume mixing ratio $(\mathrm{VMR})$ in atmospheric conditions, with $[\alpha$-pinene $]=500 \mathrm{pptv}$.

concentrations of $[\mathrm{NO}]$ range from several ppt to several hundreds of ppt. It follows that the $\alpha$-hydroxyalkyl peroxy radicals $R_{3}$ and $R_{13}$ decompose entirely to pinonaldehyde. The influence of the reaction with NO (Eq. R10) remains restricted to laboratory conditions when $[\mathrm{NO}] \geq 100 \mathrm{ppb}$. The other usual reactions of peroxy radicals compete with each other in the atmosphere. In particular, we can expect $\mathrm{HO}_{2}$, $\mathrm{CH}_{3} \mathrm{O}_{2}$, and the peroxy radicals produced by the oxidation of isoprene and the other NMOCs to play a significant role.

The dependence of the pinonaldehyde yield on the photochemical conditions in the atmosphere is illustrated by the black curves in Fig. 11. They represent the yield calculated with the box model in relatively typical atmospheric conditions, with $\left[\mathrm{CH}_{4}\right]=1.7 \mathrm{ppm},[\mathrm{CO}]=300 \mathrm{ppb}(\mathrm{a}$ higher than usual mixing ratio in order to represent the effect of other NMOCs), $\left[\mathrm{O}_{3}\right]=30 \mathrm{ppb}, \mathrm{T}=298 \mathrm{~K}$, relative humidity $=50 \%$, and $[\alpha$-pinene $]=100 \mathrm{ppt}$ (solid line) or $500 \mathrm{ppt}$ (dash dotted line). The photolysis rates are those reported in Tables 4 and 5. In these conditions, $[\mathrm{OH}]$ and $\left[\mathrm{HO}_{2}\right]$ are calculated to range between 4 and $6 \times 10^{6}$ and 3 and $4 \times 10^{8}$ molecules $\mathrm{cm}^{-3}$, respectively.

The pinonaldehyde yield varies significantly with the level of $\mathrm{NO}$ from about $10 \%$ (NO $5 \mathrm{ppt}$ ), in clean conditions to more than $50 \%$ for $\mathrm{NO} \geq 200 \mathrm{ppt}$. This variation results almost exclusively from a competition between $\mathrm{NO}$ - and $\mathrm{HO}_{2}-$ reactions of the peroxy radicals. The permutation reactions bring only a minor contribution to pinonaldehyde production. The $\alpha$-pinene concentration has therefore little influence on the product distribution. Note that the chemical interactions with other NMOCs and in particular the biogenic compounds are not taken into account in these calculations. The photooxidation of isoprene, the most abundant biogenic NMOC (Guenther et al., 1995), generates peroxy radicals bearing alcoholic and allyl functionalities (Paulson and Se- 
infeld, 1992). Half of them have self-reaction rates typical of the R1H or R2M class (see Table 2). We can expect the cross reactions between these radicals and those from $\alpha$-pinene to occur in the canopy and to offer an additional channel to the production of pinonaldehyde.

The dependence of the total primary nitrate and hydroperoxide yields with $\mathrm{NO}$ has also been calculated for typical atmospheric conditions, with $[\alpha$-pinene $]=500 \mathrm{pptv}$. As seen in Fig.12, the production of hydroperoxides is expected to be important in the atmosphere, with a yield close to $90 \%$ at very low $\mathrm{NO}_{\mathrm{x}}(1 \mathrm{ppt} \mathrm{NO})$, and as high as $30 \%$ at $100 \mathrm{pptv}$ of NO. Hydroxy hydroperoxides represent the majority of these hydroperoxides. They have low vapor pressures and high solubilities and may therefore have a strong impact on SOA formation (Bonn et al., 2004).

\section{Conclusions}

An exhaustive mechanism of the $\mathrm{OH}$-initiated oxidation of $\alpha$-pinene and pinonaldehyde developed by Peeters and coworkers has been implemented in a box model and validated against the series of experiments made by Nozière et al. (1999a). The experiments in presence of NO are well reproduced by the model. A good agreement is obtained for the yields of pinonaldehyde, acetone, total nitrates and total peroxy acyl nitrates. Pinonaldehyde production appears to be fairly well described. The concentrations of NO used in the experiments are relatively high ( $\geq 1 \mathrm{ppm})$ so that the $\alpha$ hydroxyalkyl peroxy radicals can react with NO or decompose to pinonaldehyde in competing processes. In these conditions, the pinonaldehyde yields vary between $50 \%$ to $60 \%$. In absence of NO, this yield falls to about $26 \%$ in the measurements as well as in the model simulations. The model fails, however, to reproduce the production of acetone in absence of NO, presumably because the chemistry following the ring closure reaction of $\mathrm{R}_{7} \mathrm{O}_{2}$ and the oxidation of the primary products (except pinonaldehyde) is not treated explicitly in the model.

In the atmosphere, where the NO levels lie in the range $1 \mathrm{ppt}-1 \mathrm{ppb}$, the decomposition of the $\alpha$-hydroxyalkyl peroxy radicals is dominant. Due to the competition between the reactions of the other peroxy radicals with $\mathrm{NO}, \mathrm{HO}_{2}$ and other $\mathrm{RO}_{2} \mathrm{~s}$, the yield of pinonaldehyde is predicted to vary from $10 \%$ in clean conditions to $60 \%$ in the most polluted areas. Further theoretical or laboratory studies will be required to elucidate the acetone formation channels in low $\mathrm{NO}_{\mathrm{x}}$ (i.e. atmospheric) conditions. Also, although the crude representation adopted in this study for the oxidation of the primary products (other than pinonaldehyde) appears to be sufficient for the simulations of early stages in the oxidation of $\alpha$-pinene, it is likely to be unrealistic in general conditions. Thousands of reactions will probably have to be carefully examined before the impact of these processes in the atmosphere (without mentioning the ozonolysis and nitrate- initiated oxidation of $\alpha$-pinene) can be assessed to a good degree of confidence. Since a rigorous evaluation of every possible oxidation step is not possible in a realistic time frame, focus should be given to the main oxidation pathways and to the formation of critical compounds, e.g., acetone or SOA precursors.

Acknowledgements. This work has been carried out in the framework of the Belgian Research programme on Global Change and Sustainable Development, funded by the Belgian Federal Office for Scientific, Technical and Cultural Affairs.

Edited by: A. Hofzumahaus

\section{References}

Alvarado, A., Arey, J., and Atkinson, R.: Kinetics of the gas-phase reactions of $\mathrm{OH}$ and $\mathrm{NO}_{3}$ radicals and $\mathrm{O}_{3}$ with the monoterpene reaction products pinonaldehyde, caronaldehyde, and sabinaketone, J. Atmos. Chem., 31, 281-297, 1998.

Arey, J., Atkinson, R., and Aschmann, S. M.: Product study of the gas-phase reactions of monoterpenes with the $\mathrm{OH}$ radical in the presence of $\mathrm{NO}_{\mathrm{x}}$, J. Geophys. Res., 95, 18 539-18 546, 1990.

Arey, J., Aschmann, S. M., Kwok, E. S. C., and Atkinson, R.: Alkyl nitrate, hydroxyalkyl nitrate, and hydroxycarbonyl formation from $\mathrm{NO}_{\mathrm{x}}$-air photooxidations of C5-C8 n-alkanes, J. Phys. Chem., 105, 1020-1027, 2001.

Aschmann, S. M, Reissel, A., Atkinson, R., and Arey, J.: Products of the gas phase reactions of the $\mathrm{OH}$ radical with $\alpha$ - and $\beta$-pinene in the presence of NO, J. Geophys. Res., 103, 25 553-25 561, 1998.

Atkinson, R.: Gas-phase tropospheric chemistry of organic compounds, J. Phys. Chem. Ref. Data, Monograph, 2, 215, 1994.

Atkinson, R.: Gas-phase tropospheric chemistry of volatile organic compounds: 1. Alkanes and alkenes, J. Phys. Chem. Ref. Data, 26, 215-290, 1997.

Atkinson, R.: Atmospheric chemistry of VOCs and $\mathrm{NO}_{\mathrm{x}}$, Atmos. Environ., 34, 2063-2101, 2000.

Atkinson, R., Baulch, D. L., Cox, R. A., Hampson, R. F., Kerr, J. A., Rossi, M. J., and Troe, J.: Evaluated kinetic and photochemical data for atmospheric chemistry, Supplement VII, Organic species: IUPAC subcommittee on gas kinetic data evaluation for atmospheric chemistry, J. Phys. Chem. Ref. Data, 28, 191-393, 1999.

Atkinson, R., Baulch, D. L., Cox, R. A., Crowley, J. N., Hampson, R. F., Kerr, J. A., Rossi, M. J., and Troe, J.: Summary of evaluated kinetic and photochemical data for atmospheric chemistry, 2003, IUPAC subcommittee on gas kinetic data evaluation for atmospheric chemistry, available on the subcommittee's website at http://www.iupac-kinetic.ch.cam.ac.uk, 2003.

Bacher, C., Tyndall, G. S., and Orlando, J. J.: The atmospheric chemistry of glycolaldehyde, J. Atmos. Chem., 39, 171-189, 2001.

Barnes, I., Becker, K. H., and Zhu, T.: Near UV absorption spectra and photolysis products of difunctional organic nitrates: Possible importance as $\mathrm{NO}_{\mathrm{x}}$ reservoirs, J. Atmos. Chem., 17, 353-373, 1993.

Bonn, B. and Moortgat, G. K.: New particle formation during $\alpha$ and $\beta$-pinene oxidation by $\mathrm{O}_{3}, \mathrm{OH}$ and $\mathrm{NO}_{3}$, and the influence 
of water vapour: particle size distribution studies, Atmos. Chem. Phys., 2, 183-196, 2002,

SRef-ID: 1680-7324/acp/2002-2-183.

Bonn, B., von Kuhlmann, R., and Lawrence, M., G.: High contribution of biogenic hydroperoxides to secondary organic aerosol formation, Geophys. Res. Lett., 31, L10108, doi:10.1029/2003GL019172, 2004.

Boyd, A. A., Nozière, B., and Lesclaux, R.: Kinetic study of the allylperoxy radical self-reaction and reaction with $\mathrm{HO}_{2}$, J. Chem. Soc., Faraday Trans., 92, 201-206, 1996a.

Boyd, A. A., Lesclaux, R., Jenkin, M. E., and Wallington, T. J.: A spectroscopic, kinetic and product study of the $\left(\mathrm{CH}_{3}\right)_{2} \mathrm{C}(\mathrm{OH}) \mathrm{CH}_{2} \mathrm{O}_{2}$ radical self reaction and reaction with $\mathrm{HO}_{2}$, J. Phys. Chem., 100, 6594-6603, 1996b.

Boyd, A. A. and Lesclaux, R.: The temperature dependence of the rate coefficients for $\beta$-hydroxyperoxy radical self reactions, Int. J. Chem. Kinet., 29, 323-331, 1997.

Boyd, A. A., Villenave, E., and Lesclaux, R.: Structure-reactivity relationships for the self-reactions of linear secondary alkylperoxy radicals: An experimental investigation, Int. J. Chem. Kinet., 31, 37-46, 1999.

Boyd, A. A., Villenave, E., and Lesclaux, R.: Self- and crossreactions of $\beta$-hydroxyperoxy radicals of relevance to tropospheric monoterpene oxidation: structure-activity relationships for rate coefficients, Atmos. Environ., 37, 2751-2760, 2003.

Bowman, F. M., Odum, J. R., Seinfeld, J. H., and Pandis, S. N.: Mathematical model for gas-particle partitioning of secondary organic aerosols, Atmos. Environ., 31, 3921-3931, 1997.

Canosa-Mas, C. E., Daele, V., King, M., Lopez, R., Percival, C. J., Wayne, R. P., Shallcross, D. E., and Pyle, J.: Is the reaction between $\mathrm{CH}_{3} \mathrm{C}(\mathrm{O}) \mathrm{O}_{2}$ and $\mathrm{NO}_{3}$ important in the night-time troposphere, J. Chem. Soc. Faraday Trans., 92, 2211-2222, 1996.

Damian-Iordache, V., Sandu, A., Potra, F. A., Carmichael, G. R., and Damian-Iordache, M.: KPP-A symbolic preprocessor for chemical kinetics-User's guide, Center for Global and Regional Environmental Research, The University of Iowa, Internal report, 1995.

DeMore, W. B., Sander, S. P., Golden, D. M., Hampson, R. F., Kurylo, M. J., Howard, C. J., Ravishankara, A. R., Kolb, C. E., and Molina, M. J.: Chemical kinetics and photochemical data for use in stratospheric modeling, JPL Publ., 97-4, Jet Propul. Lab., Pasadena, Calif., 1997.

Desai, J., Heicklen, J., Bahta, A., and Simonaitis, R.: The photooxidation of $\mathrm{i}-\mathrm{C}_{3} \mathrm{H}_{7} \mathrm{CHO}$ vapour, J. Photoch., 34, 137-164, 1986.

Elrod, M. J., Ranschaert, D. L., and Schneider, N. J.: Direct kinetics study of the temperature dependence of the $\mathrm{CH}_{2} \mathrm{O}$ branching channel for the $\mathrm{CH}_{3} \mathrm{O}_{2}+\mathrm{HO}_{2}$ reaction, Int. J. Chem. Kinet., 33, 363-376, 2001.

European Commission: Ozone-climate interactions, Air pollution research report No. 81, Office for Official Publications of the European Communities, Luxembourg, 143, 2003.

Fantechi, G.: Atmospheric oxidation reactions of selected biogenic volatile organic compounds (BIOVOCs): A smog chamber study, Ph.D. Thesis, KULeuven, 1999.

Fantechi G., Vereecken L., and Peeters J.: The OH-initiated atmospheric oxidation of pinonaldehyde: Detailed theoretical study and mechanism construction, Phys. Chem. Chem. Phys., 4, 5795-5805, 2002.
Finlayson-Pitts, B. J. and Pitts Jr., J. N.: Chemistry of the upper and lower troposphere, 2nd Ed., Academic Press Inc., New York, 1999.

Gardner, E. P., Sperry, P. D., and Calvert, J. G.: Photodecomposition of acrolein in $\mathrm{O}_{2}-\mathrm{N}_{2}$ mixtures, J. Phys. Chem., 91, 1922-1930, 1987.

Gierczak, T., Burkholder, J. B., Bauerle, S., and Ravishankara, A. R.: Photochemistry of acetone under tropospheric conditions, Chem. Phys., 231, 229-244, 1998.

Griffin, R. J., Cocker III, D. R., Seinfeld, J. H., and Dabdub, D. Estimate of global atmospheric organic aerosol from oxidation of biogenic hydrocarbons, Geophys. Res. Lett., 26, 2721-2724, 1999.

Guenther, A., Hewitt, C. N., Erickson, D., Fall, R., Geron, C., Graedel, T., Harley, P., Klinger L., Lerdau, M., McKay, W. A., Pierce, T., Scholes, B., Steinbrecher, R., Tallamraju, R., Taylor, J., and Zimmerman, P.: A global model of natural volatile organic compound emissions, J. Geophys. Res., 100, 8873-8892, 1995

Guenther, A., Geron, C., Pierce, T., Lamb, B., Harley, P., and Fall, R.: Natural emissions of non-methane volatile organic compounds, carbon monoxide, and oxides of nitrogen from North America, Atmos. Environ., 34, 2205-2230, 2000.

Hairer, E. and Wanner, G.: Solving ordinary differential equations II. Stiff and differential-algebraic problems, Springer series in computational mathematics, Springer-Verlag, Berlin, 1990.

Hakola, H., Arey, J., Aschmann, S. M., and Atkinson, R.: Product formation from the gas-phase reactions of $\mathrm{OH}$ radicals and $\mathrm{O}_{3}$ with a series of monoterpenes, J. Atmos. Chem., 18, 75-102, 1994.

Hallquist M., Wängberg I., and Ljungström, E.: Atmospheric fate of carbonyl oxidation products originating from $\alpha$-pinene and $\Delta^{3}$ carene: Determination of rate of reaction with $\mathrm{OH}$ and $\mathrm{NO}_{3}$ radicals, UV absorption cross sections, and vapor pressure, Environ. Sci. Technol., 31, 3166-3172, 1997.

Hatakeyama, S., Izumi, K., Fukuyama, T., Akimoto, H., and Washida, N.: Reaction of $\mathrm{OH}$ with $\alpha$-pinene and $\beta$-pinene in air: Estimate of global CO production from the atmospheric oxidation of terpenes, J. Geophys. Res., 96, 947-958, 1991.

Hippler, M., Al-Janabi, F. A. H., and Pfab, J.: Photodissociation of jet-cooled methyl and t-butyl nitrite near $380 \mathrm{~nm}$, Chem. Phys. Lett., 192, 173-178, 1992.

Horie, O. and Moortgat, G. K.: Reactions of $\mathrm{CH}_{3} \mathrm{C}(\mathrm{O}) \mathrm{O}_{2}$ radicals with $\mathrm{CH}_{3} \mathrm{O}_{2}$ and $\mathrm{HO}_{2}$ radicals between 263 and $333 \mathrm{~K}$, J. Chem. Soc. Faraday Trans., 88, 3305-3312, 1992.

IPCC, Climate change 2001: The scientific basis, contribution of working group I to the third assessment report in the intergovernmental panel on climate change, edited by: Houghton, J. T., Ding, Y., Griggs, D. J., Noguer, M., van der Linden, P. J., Dai, X., Maskell, K., and Johnson, C. A., Cambridge University Press, Cambridge, UK, 881, 2001.

Jacob, D. J., Field, B. D., Jin, E. M., Bey, I., Li, Q., Logan, J. A., and Yantosca, R. M.: Atmospheric budget of acetone, J. Geophys. Res., 107, 4100, doi:10,1029/2001JD000694, 2002.

Jang, M. and Kamens, R. M.: Newly characterized products and composition of secondary aerosols from the reaction of $\alpha$-pinene with ozone, Atmos. Environ., 33, 459-474, 1999.

Jenkin, M. E., Saunders, S. M., and Pilling, M. J.: The tropospheric degradation of volatile organic compounds: A protocol for mech- 
anism development, Atmos. Environ., 31, 81-104, 1997.

Jenkin, M. E., Boyd, A. A., and Lesclaux, R.: Peroxy radical kinetics resulting from the $\mathrm{OH}$-initiated oxidation of 1,3-butadiene, 2,3-dimethyl-1,3-butadiene and isoprene, J. Atmos. Chem., 29, 267-298, 1998.

Johnston, H. S., Davis, H. F., and Lee, Y. T.: $\mathrm{NO}_{3}$ Photolysis product channels: Quantum yields from observed energy thresholds, J. Phys. Chem., 100, 4713-4723, 1996.

Kanakidou, M., Tsigaridis, K., Dentener, F. J., and Crutzen, P. J.: Human-activity-enhanced formation of organic aerosols by biogenic hydrocarbon oxidation, J. Geophys. Res., 105, 9243-9254, 2000.

Kesselmeier, J., Bode, K., Hofmann, U., Müller, H., Schäfer, L., Wolf, A., Ciccioli, P., Brancaleoni, E., Cecinato, A., Frattoni, M., Foster, P., Ferrari, C., Jacob, V., Fugit, J.L., Dutaur, L., Simon, V., and Torres, L.: Emission of short chained organic acids, aldehydes, and monoterpenes, from Quercus ilex L. and Pinus pinea L. in relation to physiological activities, carbon budget and emission algorithms, Atmos. Environ., 31, Suppl. I, 119-134, 1997.

Knight, G., Ravishankara, A. R., and Burkholder, J. B.: UV absorption cross sections of $\mathrm{HO}_{2} \mathrm{NO}_{2}$ between 343 and $273 \mathrm{~K}$, Phys. Chem. Chem. Phys., 4, 1432-1437, 2002.

König, G., Brunda, M., Puxbaum, H., Hewitt, C. N., Duckham, S. C., and Rudolph, J.: Relative contribution of oxygenated hydrocarbons to the total biogenic VOC emissions of selected midEuropean agricultural and natural plant species, Atmos. Environ., 29, 861-874, 1995.

Kwok, E. S. C. and Atkinson, R.: Estimation of hydroxyl radical reaction rate constants for gas-phase organic compounds using a structure-reactivity relationship: An update, Atmos. Environ., 29, 1685-1695, 1995.

Larsen, B. R., Di Bella, D., Glasius, M., Winterhalter, R., Jensen, N. R., and Hjorth, J.: Gas-phase $\mathrm{OH}$ oxidation of monoterpenes: Gaseous and particulate products, J. Atmos. Chem., 38, 231-276, 2001

Librando, V., Tomaselli, G., and Tringali, G.: OH-initiated oxidation of monoterpenes: Reaction of $\alpha$-pinene, Annali di Chimica, 93, 407-413, 2003.

Lide, D. R.: CRC Handbook of Chemistry and Physics, 82th Ed., CRC Press, Boce Raton, Fla, 2001.

Lightfoot, P. D., Cox, R. A., Crowley, J. N., Destriau M., Hayman, G. D., Jenkin, M. E., Moortgat G. K., and Zabel F.: Organic peroxy radicals: Kinetics, spectroscopy and tropospheric chemistry, Atmos. Environ., 26A, 1805-1961, 1992.

Madronich, S. and Calvert, J. G.: Permutation reactions of organic peroxy radicals in the troposphere, J. Geophys. Res., 95, 5697$5715,1990$.

Madronich, S. and Flocke, S.: The role of solar radiation in atmospheric chemistry, Handbook of Environmental Chemistry, edited by: Boule, P., Springer-Verlag, Heidelberg, 1998.

Makar, P. A.: The estimation of organic gas vapour pressure, Atmos. Environ., 35, 961-974, 2001.

Molina, L. T. and Molina, M. J.: Absolute absorption cross sections of ozone in the 185 to $350 \mathrm{~nm}$ wavelength range, J. Geophys. Res., 91, 14 501-14 508, 1986.

Müller, J. F. and Brasseur, G.: Sources of upper tropospheric $\mathrm{HO}_{\mathrm{x}}$ : a three-dimensional study, J. Geophys. Res., 104, 1705-1715, 1999.
Nozière, B. and Barnes, I.: Evidence for formation of a PAN analogue of pinonic structure and investigation of its thermal stability, J. Geophys. Res., 103, 25 587-25 597, 1998.

Nozière, B., Barnes, I., and Becker, K. H.: Product study and mechanisms of the reactions of $\alpha$-pinene and of pinonaldehyde with OH radicals, J. Geophys. Res., 104, 23 645-23 656, 1999a.

Nozière, B., Spittler, M., Ruppert, L., Pons, M., and Wirtz, K.: Kinetics of the reactions of pinonaldehyde with $\mathrm{OH}$ radicals and with $\mathrm{Cl}$ atoms, Int. J. Chem. Kinet., 31, 291-301, 1999 b.

Orlando, J. J., Nozière, B., Tyndall, G. S., Orzechowska, G. E.: Paulson, S.E., and Rudich, Y., Product studies of the $\mathrm{OH}-$ and ozone-initiated oxidation of some monoterpenes, J. Geophys. Res., 105, 11 561-11 572, 2000.

Paulson, S. E. and Seinfeld, J. H.: Development and evaluation of a photooxidation mechanism for isoprene, J. Geophys. Res., 97, 20703-20715, 1992.

Peeters, J., Vereecken, L., and Fantechi, G.: the detailed mechanism of the $\mathrm{OH}$-initiated atmospheric oxidation of $\alpha$-pinene: a theoretical study, Phys. Chem. Chem. Phys., 3, 5489-5504, 2001.

Raber, W. H. and Moortgat, G. K.: Progress and problems in atmospheric chemistry, edited by: Barker, J. R., Word Scientific Publ. Co., Singapore, 318-373, 1995.

Rinne, J., Hakola, H., Laurila, T., and Rannik, Ü.: Canopy scale monoterpene emissions of Pinus sylvestris dominated forests, Atmos. Environ., 34, 1099-1107, 2000.

Rowley, D. M., Lesclaux, R., Lightfoot, P. D., Hughes, K., Hurley, M. D., Rudy, S., and Wallington, T. J.: Kinetic and mechanistic studies of the reaction of neopentylperoxy radicals with $\mathrm{HO}_{2}$, J. Phys. Chem., 96, 7043-7048, 1992.

Sander, S. P., Friedl, R. R., DeMore, W. B., Golden, D. M., Kurylo, M. J., Hampson, R. F., Huie, R. E., Moortgat, G. K., Ravishankara, A. R., Kolb, C. E., and Molina, M. J.: Chemical kinetics and photochemical data for use in stratospheric modeling Supplement to Evaluation 12: Update of Key Reactions, JPL Publ., 00-3, 2000.

Saunders, S. M., Jenkin, M. E., Derwent, R. G., and Pilling, M. J.: Protocol for the development of the Master Chemical Mechanism MCM v3 (Part A): Tropospheric degradation of non-aromatic volatile organic compounds, Atmos. Chem. Phys., 3, 161-180, 2003,

SRef-ID: 1680-7324/acp/2003-3-161

Tadic, J., Juranic, I., and Moortgat, G. K.: Pressure dependence of the photooxidation of selected carbonyl compounds in air: $n-$ butanal and n-pentanal, J. Photoch. A, 143, 169-179, 2001a.

Tadic, J., Juranic, I., and Moortgat, G. K.: Photooxidation of nhexanal, Molecules, 6, 287-299, 2001b.

Tadic, J. M., Juranic, I. O., and Moortgat, G. K.: Photooxidation of $n$-heptanal in air: Norrish type I and II processes and quantum yield total pressure dependency, J. Chem. Soc. Perkin Trans., 2, 135-140, 2002.

Talukdar, R. K., Burkholder, J. B., Hunter, M., Gilles, M. K., Roberts, J. M., and Ravishankara, A. R.: Atmospheric fate of several alkyl nitrates, J. Chem. Soc. Faraday Trans., 93, 27972805, 1997.

Tomas, A. and Lesclaux, R.: Self-reaction kinetics of the $\left(\mathrm{CH}_{3}\right)_{2} \mathrm{CHC}(\mathrm{O}) \mathrm{O}_{2}$ and $\left(\mathrm{CH}_{3}\right)_{3} \mathrm{CC}(\mathrm{O}) \mathrm{O}_{2}$ acylperoxy radicals between 275 and 363 K, Chem. Phys. Lett., 319, 521-528, 2000.

Tsigaridis, K. and Kanakidou, M.: Global modelling of secondary organic aerosol in the troposphere: a sensitivity analysis, Atmos. 
Chem. Phys., 3, 1849-1869, 2003,

\section{SRef-ID: 1680-7324/acp/2003-3-1849.}

Tyndall, G. S., Cox, R. A., Granier, C., Lesclaux, R., Moortgat, G. K., Pilling, M. J., Ravishankara, A. R., and Wallington, T. J.: Atmospheric chemistry of small organic peroxy radicals, J. Geophys. Res., 106, 12 157-12 182, 2001.

Vanhees, I., Van Den Bergh, V., Shildermans, R., De Boer, R., Compernolle, F., and Vinckier, C.: Determination of the oxidation products of the reaction between $\alpha$-pinene and $\mathrm{OH}$-radicals by high-performance liquid chromatography, J. Chromatogr. A, 915, 75-83, 2001.

Vereecken, L. and Peeters, J.: Non-traditional (per)oxy ring-closure paths in the atmospheric oxidation of isoprene and monoterpenes, J. Phys. Chem. A., 108,5197-5204,2004
Villenave, E. and Lesclaux, R.: Kinetics and atmospheric implications of peroxy radical cross reactions involving the $\mathrm{CH}_{3} \mathrm{C}(\mathrm{O}) \mathrm{O}_{2}$ radical, J. Geophys. Res., 103, 25 273-25 285, 1998.

Warneck, P.: Photodissociation of acetone in the troposphere: an algorithm for the quantum yield, Atmos. Environ., 35, 5773-5777, 2001.

Wisthaler A., Jensen, N. R., Winterhalter, R., Lindinger, W., and Hjorth, J.: Measurements of acetone and other gas phase product yields from the $\mathrm{OH}$-initiated oxidation of terpenes by protontransfer reaction mass spectrometry (PTR-MS), Atmos. Environ., 35, 6181-6191, 2001. 